\title{
Environmentally Friendly Controlled Synthesis of Gold Nanostars with Collagen by One-Step Reduction Method
}

\author{
Quoc Khuong Vo $\mathbb{D}^{1},{ }^{1}$ Anh Thu Nguyen, ${ }^{1}$ Huu Tien Ho, ${ }^{2}$ Le Thanh Nguyen Huynh $\mathbb{D},{ }^{1}$ \\ Thi Phuong Phong Nguyen ${ }^{(D)}{ }^{1}$ and Thi Hong-Tham Nguyen ${ }^{3,4}$ \\ ${ }^{1}$ Faculty of Chemistry, Ho Chi Minh City University of Science, Vietnam National University Ho Chi Minh City, 227 Nguyen Van \\ Cu Street, Dist 5, Ho Chi Minh City 70000, Vietnam \\ ${ }^{2}$ Faculty of Engineering, Van Lang University, 45 Nguyen Khac Nhu Street, Dist. 1, Ho Chi Minh City 700000, Vietnam \\ ${ }^{3}$ Faculty of Chemical Engineering and Food Technology, Nguyen Tat Thanh University, Ho Chi Minh City, Vietnam \\ ${ }^{4}$ Institute of Environmental Sciences, Nguyen Tat Thanh University, Ho Chi Minh City 70000, Vietnam
}

Correspondence should be addressed to Thi Phuong Phong Nguyen; ntpphong@hcmus.edu.vn

Received 6 April 2021; Revised 29 November 2021; Accepted 30 December 2021; Published 29 January 2022

Academic Editor: Surinder Singh

Copyright (c) 2022 Quoc Khuong Vo et al. This is an open access article distributed under the Creative Commons Attribution License, which permits unrestricted use, distribution, and reproduction in any medium, provided the original work is properly cited.

\begin{abstract}
In this study, gold nanostars (AuNSs) were prepared by a facile and environmentally friendly method through the one-step reduction process with collagen as the stabilizing agent. The use of collagen, a highly biocompatible protein with many functional amines groups, can facilitate the simultaneous controlled synthesis and surface protecting of gold nanoparticles in one step. This synthetic process was operated in the aqueous solution of tetrachloroauric acid $\left(\mathrm{HAuCl}_{4}\right)$ at room temperature, in which ascorbic acid serves as a reductive agent. The influence of collagen concentration $(0.02-0.06 \mathrm{mM})$ on the morphology of AuNSs was carefully studied to clarify its dual roles as stabilizing and controlling agents for the growth of the particles. Besides that, by simply adjusting reaction components such as the molar ratio of ascorbic acid to $\mathrm{HAuCl}_{4}$ and $\mathrm{pH}$ value, the length of the AuNS tips was also controlled. This study could offer a novel modified approach in the controlled synthesis process of AuNSs with the biomolecules collagen. The resulting AuNSs were then characterized by ultraviolet-visible (UV-Vis) spectroscopy, transmission electron microscopy (TEM), high-resolution transmission electron microscopy (HRTEM), energydispersive X-ray spectroscopy (EDS), zeta potential, Fourier transform-infrared (FT-IR) spectroscopy, X-ray diffraction (XRD), and circular dichroism (CD), as well as selected area electron diffraction (SAED). UV-Vis spectroscopy showed the formation of AuNSs with the maximum surface plasmon resonance peak at $600-639 \mathrm{~nm}$. TEM results revealed that the average particle size of the AuNSs stabilized by the collagen ranged from $27.39 \mathrm{~nm}$ to $41.55 \mathrm{~nm}$, depending on the experimental composition and the $\mathrm{pH}$ values. HRTEM, EDS, and SAED results prove a more precise insight into the formation of pure gold nanocrystals. Analysis of the current results may also help better understand the growth mechanism of AuNSs during the synthesis process in the presence of collagen. The Au concentration quantified by the inductively coupled plasma mass spectrometry (ICP-MS) technique after separating and decomposing with microwave-assisted digestion exhibits that the synthesis of AuNSs has a high yield of $88.62 \%$. Additionally, the colloidal stability of AuNS-collagen against different $\mathrm{NaCl}$ concentrations, $\mathrm{pH}$, temperatures, and storage time was also examined through UV-Vis spectroscopy. The investigation results reveal that AuNS-collagen remains stable in $\mathrm{NaCl} 2.0 \%(\mathrm{w} / \mathrm{v})$, from mildly acidic to neutral $\mathrm{pH}(4-7)$, below the temperature of $40^{\circ} \mathrm{C}$, and within 21 days postsynthesis. The AuNS synthesized by this eco-friendly method is promising for many potential applications in biomedical field.
\end{abstract}

\section{Introduction}

In recent years, significant efforts have been made to develop different synthetic strategies to prepare exceptionally aniso- tropic gold nanostructures for various applications because of their intrinsic optical [1] and chemical properties [2]. Especially in biomedical fields, controlling the size and shape of gold nanoparticles is necessary, as these properties have 
many effects on pharmacokinetics. Among the various anisotropic morphologies of gold nanoparticles, starshaped nanostructure has attracted significant interest due to its unique optical properties [3], known as high localization of surface plasmon resonance $[4,5]$. Controlled synthesis of gold nanoparticles generally involves fine-tuning the experimental parameters, such as reagent composition [2], surfactant concentration [6], pH conditions [7], and the reaction temperature $[2,8]$ to obtain particles with desirable morphology. To date, many groups have developed various synthetic approaches of shape control through a two-step process, together with using surfactant as the template for directing nanoparticle growth [6,9]. Vijayaraghavan and coworkers showed the well-defined and high-yield multibranched gold nanoparticles using a gemini cationic surfactant $\mathrm{N}, \mathrm{N}, \mathrm{N}, \mathrm{N}^{\prime}$-tetramethyl-N,N-ditetradecylethane1,2-diammonium bromide $\left(\mathrm{C}_{14} \mathrm{C}_{2} \mathrm{C}_{14} \mathrm{Br}_{2}\right)$ [10]. Baginsky et al. used cetyltrimethylammonium bromide (CTAB) to tune the length of branches and modified the surfaces of particles with chitosan [11]. Phan and coworkers can obtain a well-defined star-shaped structure in chitosan solution through selective $\mathrm{pH}$ levels of 1 and 3 [12]. Zhang and coworkers reported that by changing the ratios of cetyltrimethylammonium bromide (CTAB) and cetyltrimethylammonium chloride (CTAC), multibranched gold nanoparticles could be prepared via a convenient seed-mediated method [13]. Despite abundant reports on the successful synthesis of branch-shaped gold nanoparticles, most synthetic strategies miss the mark of safety for biomedical applications. Furthermore, to our knowledge, attempts at synthesizing starliked gold nanostructure through a one-step reduction approach using biopolymer collagen are severely lacking.

Collagen is the most abundant extracellular matrix protein and the main component of connective tissue $[14,15]$. Due to advantageous properties such as nontoxicity, good biodegradability, and biocompatibility [16], the use of collagen as the natural polymer in the field of metal nanoparticle preparation has been intensively growing in recent years. This fibrous protein has a unique structure of triple-helical chains held together by hydrogen bonds and Vander Waals forces [14]. In the controlled synthesis of gold nanoparticles, there are several key advantages to use collagen as the stabilizing agent. When changing the environmental conditions such as $\mathrm{pH}$ and temperature, these interactions could be disrupted and lead to the transformation of the triple helix to the denatured state, in which collagen exists as random coil conformation [16]. These random coils could be deposited effectively onto the specific crystal facets of particles through their abundant functional groups and then slow down the growth of nanoparticles along with these facets. Thus, they can induce preferential growth along other directions to form the multibranched nanostructure. In addition, utilizing collagen can improve the size-controlled synthesis of gold nanoparticles based on the inner limit pore size of the polymeric matrixes, which can act as the template for the growth of nanoparticles [17].

Herein, we report an efficiently facile one-step procedure to synthesize star-liked shape and high-yield nanoparticles using natural protein collagen with ascorbic acid as a reduc- ing agent (Scheme 1). We have utilized a modified method by replacing the conventional surfactant CTAB with collagen molecules and performed a systematic study by governing reaction parameters to prepare the star-shaped gold nanostructure. Besides, to elucidate the protecting role of collagen in the controlled synthesis of AuNSs, a low concentration of collagen was used in this experiment.

\section{Experimental}

2.1. Materials and Methods. Tetrachloroauric (III) acid trihydrate $\left(\mathrm{HAuCl}_{4} .3 \mathrm{H}_{2} \mathrm{O}, 99.5 \%\right)$, sodium borohydride $\left(\mathrm{NaBH}_{4}, 96.0 \%\right)$, silver nitrate $\left(\mathrm{AgNO}_{3}, 99.0 \%\right)$, L (+)-ascorbic acid $\left(\mathrm{C}_{6} \mathrm{H}_{8} \mathrm{O}_{6}, 99.0 \%\right)$, trisodium-citrate, and hydrogen peroxide $\left(\mathrm{H}_{2} \mathrm{O}_{2}, 30 \%\right)$ were purchased from SigmaAldrich (Darmstadt, Germany). Collagen from calfskin (Bornstein and Traub Type I, powder, C9791) was obtained from Sigma-Aldrich (Darmstadt, Germany). Deionized (DI) water ( $>18 \mathrm{MW}$, Millipore) (conductivity was below $4.3 \mu \mathrm{S} / \mathrm{cm}$ ) was used during the preparation of the gold nanostars. All chemical reagents and solvents were used without further purification.

2.2. One-Step Preparation of Gold Nanostars. Collagen solution was prepared by dissolving an amount of purified collagen powder with sonication in deionized (DI) water $(<4.3 \mu \mathrm{S} / \mathrm{cm})$ for $45 \mathrm{~min}$ and then vigorously stirring at room temperature to make up collagen concentration at $0.01,0.02$, $0.03,0.04,0.05$, and $0.06 \mathrm{mM}$. In a typical synthesis procedure, $80 \mu \mathrm{L}$ aqueous solution of $\mathrm{HAuCl}_{4}$ of $25 \mathrm{mM}$ was flush mixed with $20 \mu \mathrm{L}$ solution $\mathrm{AgNO}_{3}$ of $10 \mathrm{mM}$ and $2.0 \mathrm{~mL}$ of collagen $0.05 \mathrm{mM}$ and then gently stirred at $600 \mathrm{rpm}$ for 15 minutes at room temperature. Afterward, $1.0 \mathrm{~mL}$ of freshly prepared ascorbic acid solution $(5.0 \mathrm{mM})$ was added slowly into the above solution under magnetic stirring for 30 minutes, and the volume was adjusted to $20 \mathrm{~mL}$ with DI water. The color of the colloidal solution changed from light yellow to red, red-purple, and dark blue for 30 seconds, and this solution was then kept at $25^{\circ} \mathrm{C}$ for three hours. The nanoparticles were formed at selected $\mathrm{pH}$ conditions of 3.0, 4.0, and 5.0.

\subsection{Characterization}

2.3.1. Particles Size and Shape Analysis. The transmission electron microscope (TEM) was used to elaborate the obtained AuNSs using a JEM-1400, Japan. First, the colloidal solution was added in a small quantity onto a carbon-coated copper mesh (300-mesh, Ted Pella, Inc., Redding, CA, USA). The solution was then allowed to dry naturally at room temperature before being subjected to TEM observation. The average size and size distribution of AuNS particles were calculated by measuring 100 particles in certain areas in microphotographs. The high-resolution TEM analysis was carried out using an FEI Tecnai G2 F20, USA, at an accelerating voltage of $200 \mathrm{kV}$. Energy-dispersive X-ray spectroscopy (EDS) was obtained with a JEOL JSM $7600 \mathrm{~F}$ at $30 \mathrm{kV}$.

2.3.2. Ultraviolet (UV) Spectra. The UV-Vis absorption spectroscopy of AuNS colloidal solution was recorded by a UV- 


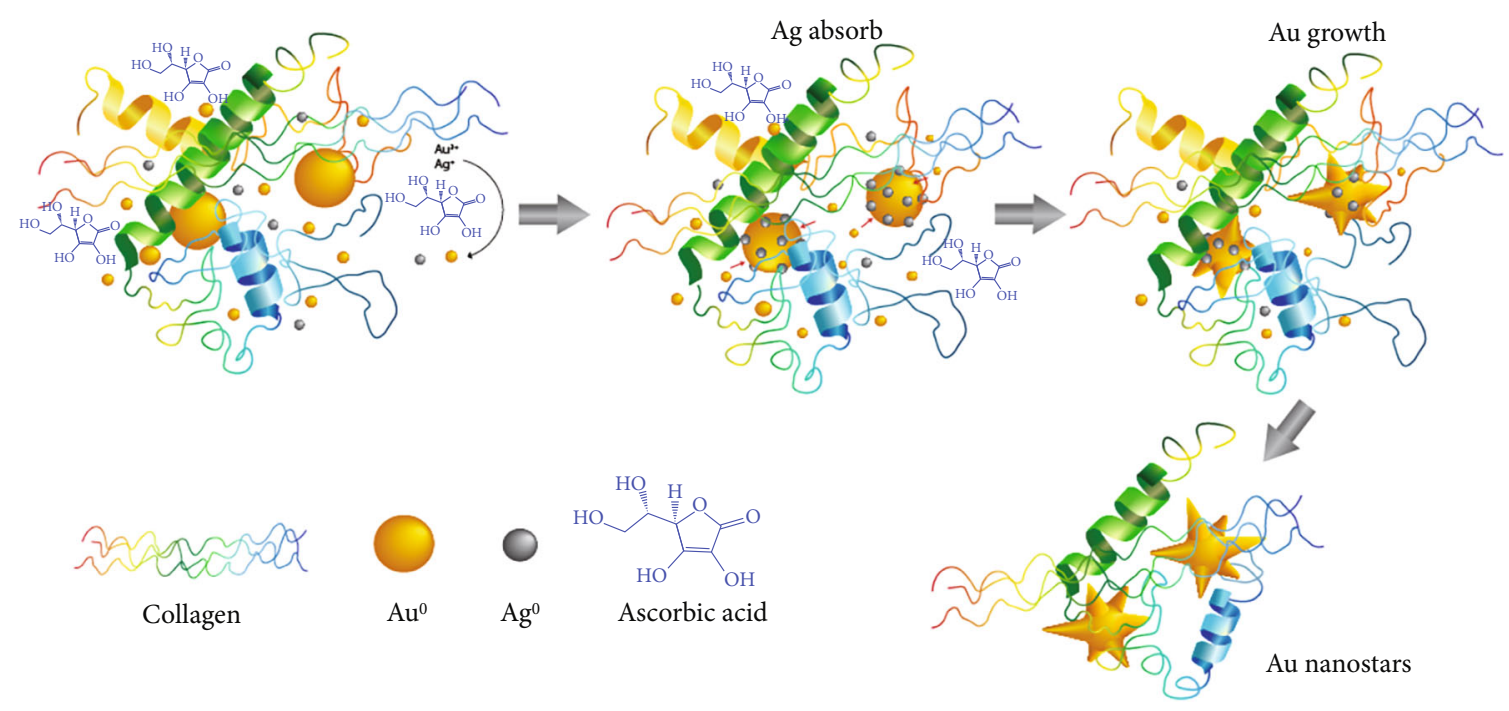

Scheme 1: The formation of gold nanostars in the presence of collagen.

Vis NIR-V670 spectrophotometer (JASCO, Japan). The UV-Vis spectrum testing range was $300-800 \mathrm{~nm}$ with a scanning rate of $200 \mathrm{~nm}$ per minute using quartz cuvettes (1 cm path length).

2.3.3. X-Ray Diffraction. The X-ray diffraction (XRD) was carried out on a D8 Advance-Bruker, Germany, with $\mathrm{Cu}-$ $\mathrm{K} \alpha$ radiation, operated at $40 \mathrm{kV}$. AuNS powder samples obtained by centrifuging and subsequently drying under vacuum at room temperature were evenly placed on a grooved glass sheet and compacted with another glass slide and then subjected to X-ray at a scanning rate of $0.02 \% \mathrm{~min}$ in the $2 \theta$ range from $20^{\circ}$ to $70^{\circ}$. Wide-angle XRD showed a face-centered cubic structure; five peaks are assigned to (111), (200), and (220) facets. The selected area electron diffraction (SAED) was used to determine the crystalline structure of AuNSs.

2.3.4. Zeta Potential Analysis. The zeta potential of collagen, gold nanoparticles synthesized without collagen, and collagen-stabilized AuNS was determined at $25^{\circ} \mathrm{C}$ using a Zetasizer SZ-100 (Horiba, Instrument Co. Ltd, Kyoto, Japan). Disposable zeta potential cells for aqueous measurements $(100 \mu \mathrm{L})$ were used as the sample container. The $\mathrm{pH}$ of the collagen solution was adjusted from 3.0 to 5.0 using the aqueous solution of $\mathrm{HCl}$ and $\mathrm{NaOH}(1.0 \mathrm{M})$. The sample was injected into a cell, and calculation of the zeta potential was based on the particle electrophoretic mobility measurement results.

2.3.5. Fourier Transform-Infrared (FI-IR) Spectroscopy. Fourier transform-infrared (FT-IR) spectroscopy spectra were collected on a Tensor 27-Bruker spectrometer, and the samples were prepared by mixing a $3.0 \mathrm{~mL}$ volume of AuNS colloidal solution (synthesized with the collagen concentration of $0.05 \mathrm{mM}$ at $\mathrm{pH} 4.0$ ) with $\mathrm{KBr}$ at ratio 2$5 \%$, operating wavenumber in the range of $400-4000 \mathrm{~cm}^{-1}$. The AuNS-collagen, type I collagen spectra were analyzed to detect covalent bonds of functional groups and the interaction of the stabilizing agent on the nanoparticles. All obtained spectra were processed with the Bruker Opus 7.0 software.

2.3.6. Separation Method for Quantification of the AuNSCollagen Colloidal Solution. The separation process was modified based on Galazzi et al. [18] and Arruda et al. method [19]. The total amount of formed gold nanoparticles and the remaining Au ions unreacted was determined in the colloidal solution at the end of synthesis. The AuNS-collagen colloidal solutions were centrifuged at $9000 \mathrm{rpm}$ to separate into supernatant and gold nanoparticle sediment. The centrifugation time was optimized due to the observation of the plasmonic peak of AuNSs in the UV-Vis spectrum of the supernatant until no characteristic peak of gold nanostar was detected. The centrifugation time was investigated from 15 to 80 minutes. The sediment fraction was then resuspended in ultrapure water and then determined the presence of AuNSs by UV-Vis spectroscopy.

2.3.7. Microwave-Assisted Acid Digestion and Gold Quantification by ICP-MS. The separation fractions of AuNS sample were decomposed by microwave-assisted acid digestion based on EPA (Environmental Protection Agency) method 3052 [20] prior to ICP-MS analysis. In the sample preparation procedure, $0.5 \mathrm{~g}$ sample was digested in a mixture of $9.0 \mathrm{~mL}$ concentrated nitric acid (65\%), $3 \mathrm{~mL}$ of $\mathrm{HF}$, and $2.0 \mathrm{~mL}$ of additional hydrochloric acid (30\%) and added into the inert polymeric microwave digestion vessel. All vessels were rinsed with $\mathrm{HNO}_{3}$ solution (1.3\%) before use. The vessel contents were then sealed and heated for 15 minutes using Speedwave XPERT-Microwave Pressure Digestion System provided a nominal $1000 \mathrm{~W}$ of power and the magnetron of $2000 \mathrm{~W}$. The samples were digested in the program of temperature ramp of 5.5 minutes to $180 \pm 5^{\circ} \mathrm{C}$, followed by the hold time of 9.5 minutes at $180 \pm 5^{\circ} \mathrm{C}$ to complete the reactions. After cooling down to ambient temperature, 
the vessel contents were then filtered through $0.45 \mu \mathrm{m}$ membrane filters. Subsequently, the digested samples were diluted up to $25 \mathrm{~mL}$ with ultrapure water for determining the gold content by ICP-MS. At least three replicates of the sample investigation were performed, and the preparation procedures were conducted on the same day of analysis. The Elan DRCII (Perkin Elmer SCIEX) ICP-MS equipped with a Meinhard concentric nebulizer and a cyclonic spray chamber were used to determine gold concentrations in the samples. The instrumental and measurement parameters of ICP-MS techniques are based on the study of Batista et al. [21], presented in Table 1.

2.3.8. Circular Dichroism (CD) Spectra. The collagen and AuNS-collagen samples with the collagen concentration of $0.05 \mathrm{mM}$ were prepared to determine the protein secondary structure. Spectrum scanning was recorded by the Chirascan CD spectrometer (Applied Photophysics, Surrey, UK) using a $1 \mathrm{~mm}$ optical path length quartz cuvette at the scanning range $200-400 \mathrm{~nm}$, scanning rate $100 \mathrm{~nm} / \mathrm{min}$, interval time $1.0 \mathrm{~nm}$. The blank correction was carried out with ultrapure water, and all samples were analyzed at ambient temperature. The secondary structure content was calculated and evaluated through the CNDD Circular Spectroscopy Deconvolution 2.1 software.

2.3.9. Stability of AuNS-Collagen at Different Salt Concentrations, pH, Temperatures, and Storage Time. The stability of AuNS-collagen against different $\mathrm{pH}$, salt concentrations, and temperatures was studied based on $\mathrm{Wu}$ et al. [22] and Yang et al. [23] reports. The AuNS-collagen colloidal solutions were dissolved to $0.5 \%(\mathrm{w} / \mathrm{v})$ in DI water. Then, add $5.0 \mathrm{~mL}$ volume of $\mathrm{NaCl}$ solutions with different salt concentrations $(0,1.0,2.0,3.0$, and $4.0 \%(\mathrm{w} / \mathrm{v}))$ into the above colloidal solutions. For evaluating the influence of $\mathrm{pH}$, the colloidal solutions were adjusted $\mathrm{pH}(1,4,7$, and 10) with the aqueous solutions of $\mathrm{HCl}$ and $\mathrm{NaOH}(0.1 \mathrm{M})$ and kept at room temperature for at least 30 minutes. The colloidal stability against temperatures was determined by heating the AuNS-collagen samples at different temperatures (25, $30,35,40,45$, and $50^{\circ} \mathrm{C}$ ) before determining the plasmonic peaks for gold nanoparticles with UV-Vis spectroscopy. Besides, the AuNS-collagen samples were stored for 21 days at room temperature to study the colloidal stability.

\section{Result and Discussion}

3.1. Influence of $p H$ Levels. AuNSs stabilized by collagen were synthesized through reducing gold chloride with an appropriate amount of ascorbic acid at the low $\mathrm{pH}$ level. The reducing agent plays a critical role in forming anisotropic gold nanostructures and mainly governs the generation rate of $\mathrm{Au}^{\circ}$ atom from the reduction of $\mathrm{AuCl}_{4}^{-}$ions. The selection of ascorbic acid as the mild reducing agent could limit the generation stage of growth species $\left(\mathrm{Au}^{\circ}\right.$ atom), and the growth stage of gold nanoparticles would prevail. Thus, the initial nanocrystals predominantly grow into larger particles of particular morphologies than the generation of new nuclei. Additionally, the suitable $\mathrm{pH}$ con-
TABLE 1: Instrumental parameters and operating conditions of ICP-MS for gold qualification.

\begin{tabular}{|c|c|}
\hline Instrument & Elan DRCII (Perkin Elmer SCIEX) \\
\hline Nebulizer & Meinhard \\
\hline Spray chamber & Cyclonic \\
\hline Torch injector & Quartz for clinical sample $(2.0 \mathrm{~mm})$ \\
\hline Auto lens & On \\
\hline RF power $(\mathrm{W})$ & 1100 \\
\hline Gas flow rates $\left(\mathrm{L} \cdot \mathrm{min}^{-1}\right)$ & $\begin{array}{c}\text { Nebulizer } 0.86 \text {, plasma } 15 \text {, auxiliary } \\
1.2\end{array}$ \\
\hline Interface & Platinum cones \\
\hline Sampler & $1.1 \mathrm{~mm}$ \\
\hline Skimmer & $0.9 \mathrm{~mm}$ \\
\hline Scanning mode & Peak hopping \\
\hline Integration time (ms) & 2000 \\
\hline Replicates & 3 \\
\hline Sweeps & 40 \\
\hline Readings & 1 \\
\hline Dwell time (ms) & 50 \\
\hline Lens voltage $(\mathrm{V})$ & 6.0 \\
\hline $\begin{array}{l}\text { Sample uptake rate } \\
\left(\mathrm{mL} \cdot \mathrm{min}^{-1}\right)\end{array}$ & 1.0 \\
\hline
\end{tabular}

dition also plays a valuable role in synthesizing AuNSs through the remarkable effect on the reduction rate of $\mathrm{AuCl}_{4}^{-}$ions and the collagen conformation. The influence of $\mathrm{pH}$ conditions on the formation of AuNSs was firstly investigated in the presence of collagen by UV-Vis spectra and TEM images.

When performing the reaction at $\mathrm{pH} 3.0$ using a collagen concentration of $0.04 \mathrm{mM}$, the blue colloidal solution was obtained; it was analyzed by UV-Vis spectroscopy which revealed the surface plasmon peak at $713 \mathrm{~nm}$ (curve red- $\mathrm{pH} 3.0$ ), corresponding to the signature for starshaped gold nanoparticles [1]. The control experiment was carried out without using collagen, and a colorless colloidal solution was observed, possibly because only $\mathrm{Au}^{+}$ions were generated in the solution. Thus, it was found that the collagen showed a supported effect on the reduction of $\mathrm{AuCl}_{4}{ }^{-}$to form the star-shaped nanostructures, evidenced by the change from colorless to the blue of colloidal solution. UVVis spectra of AuNSs dispersed in aqueous solutions in Figure 1 revealed that surface plasmon resonance peaks shifted to the longer wavelength from 626 to $713 \mathrm{~nm}$, when $\mathrm{pH}$ was decreased from 5.0 to 3.0 , respectively (Table 2). Furthermore, the spectra of Au colloidal solution synthesized at the $\mathrm{pH}$ of 4.0 also exhibited the broad absorption band with a peak that appeared at the wavelength of $626 \mathrm{~nm}$ (Figure 1, curve black), indicating the large size distribution of AuNSs [3]. Accordingly, the TEM images in Figure 2 also confirm that most of the gold nanoparticles were star-liked in shape. The elongation of the branched tips on AuNSs was also observed with the increase of $\mathrm{pH}$ to 4.0 (Figure 2(c)). The representative TEM image of the sample 


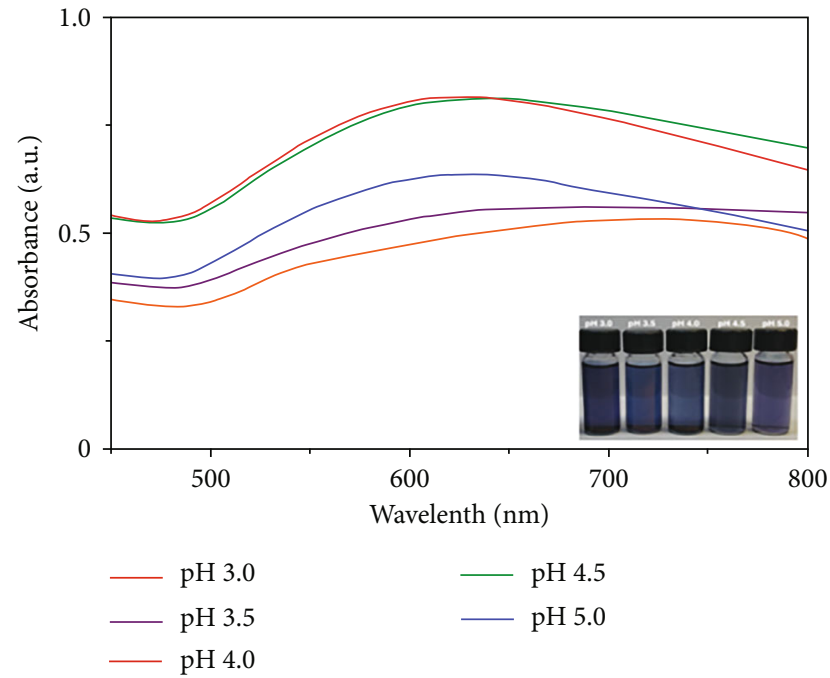

FIGURE 1: UV-Vis spectra of gold nanostructures obtained with different $\mathrm{pH}$ levels of 3.0, 3.5, 4.0, 4.5, and 5.0; inserts display the color of Au colloids (right inset).

TABLE 2: UV-Vis data of star-shaped gold nanostructures prepared at various $\mathrm{pH}$ levels of 3.0, 3.5, 4.0, 4.5, and 5.0.

\begin{tabular}{lcc}
\hline $\mathrm{pH}$ values & Wavelength $(\mathrm{nm})$ & Absorbance (a.u.) \\
\hline 3.0 & 713 & 0.535 \\
3.5 & 689 & 0.562 \\
4.0 & 626 & 0.817 \\
4.5 & 636 & 0.811 \\
5.0 & 626 & 0.637 \\
\hline
\end{tabular}

prepared at pH3.0 (Figure 2(a)) showed that the size of obtained AuNSs was distributed from $15 \mathrm{~nm}$ to $40 \mathrm{~nm}$, with short branches emanating from the initial small gold nanocrystals (Figure 2(b)).

3.2. Influence of Collagen Concentration. The collagen used in this study was type I, which exists as its nanofiber that forms the triple helix structure, and the monomer length is about $300 \mathrm{~nm}$. Increased collagen concentration from 0.01 to $0.06 \mathrm{mM}$ showed a significant decrease in absorbance intensity in the UV-Vis spectra (Figure 3). Besides, a remarkable redshift of plasmon peak from $567 \mathrm{~nm}$ to a longer wavelength of $638 \mathrm{~nm}$ was also detected with increased collagen concentration from $0.01 \mathrm{mM}$ to $0.06 \mathrm{mM}$, predicting the growth of larger particles in the colloidal solution $[1,24]$. The redshift was accompanied by a broadening of the band in the long-wavelength region. These results suggest that the nanoparticle in samples using collagen concentrations of $0.05 \mathrm{mM}, 0.06 \mathrm{mM}$ could possess shapes different from spherical, and the particles' elongations have occurred. Based on the previous experimental studies [25, 26], the elongation of the tips on star-shaped nanoparticles is associated with the redshift in the plasmon peaks [3]. Therefore, based on the UV-Vis spectroscopy shown in Figure 3 (curve black), possibly the tips could grow longer with increased collagen concentration $0.06 \mathrm{mM}$. These results clarify the essential role of collagen in the controlled synthesis of AuNSs, directly affecting the growth of nanoparticles to form anisotropic shapes.

The TEM results of the colloidal sample confirm that the particles are primarily star-liked in shape, and the size of AuNSs can be governed by adjusting the collagen concentration. In the synthesis with low concentrations of collagen at 0.02 and $0.03 \mathrm{mM}$ (Figures $4(\mathrm{a})-4(\mathrm{~d})$ ), the average size of particles ranges from $32.27 \mathrm{~nm}$ to $27.39 \mathrm{~nm}$, respectively. It is also noticed that the tips of the star-liked gold nanoparticles in these samples are blunt. With the increase in collagen concentration from $0.04 \mathrm{mM}$ to $0.05 \mathrm{mM}$ (Figures $4(\mathrm{e})-$ 4(h)), the average size of particles increases from $29.79 \mathrm{~nm}$ to $41.55 \mathrm{~nm}$, and the tips of nanoparticles become more extended and sharper. Additionally, the particles in the samples synthesized with the higher concentration of $0.04 \mathrm{mM}$ and $0.05 \mathrm{mM}$ (Figures $4(\mathrm{e})$ and $4(\mathrm{~g})$ ) were prone to form more separately and discretely in colloidal systems than particles prepared with lower collagen concentration $(0.02 \mathrm{mM}$ and $0.03 \mathrm{mM}$ ) (Figures $4(\mathrm{a})$ and $4(\mathrm{c})$ ). However, the gold nanoparticle synthesized with a higher collagen concentration of $0.06 \mathrm{mM}$ was unstable for a short time and tended to self-agglomerate when analyzed with the TEM technique. TEM results proved that collagen concentration could be the crucial factor in controlling the length of the nanostar tips. It was noticed that collagen molecules could also bind to AuNS particles through cysteine residues, stabilizing the particles through the electrostatic interaction. Previous studies have shown that collagen molecules bind to gold nanoparticles through electrostatic interaction because they possess many charge moieties to attract the gold nanoparticles with polarity $[27,28]$. Significantly, collagen can tightly bind to gold nanoparticles with small size on its matrix, but in collapsed collagen structures, and inability in uncollapsed collagen structures [28]. Thus, it is necessary to combine appropriate $\mathrm{pH}$ conditions with suitable collagen concentrations to stabilize collagen in the controlled synthesis of AuNSs. Based on the diffusion-limited growth mechanism [29], as increased collagen concentration at the allowable threshold, the diffusion of the Au atom through the colloidal solution effectively decreased due to the higher viscosity of collagen. Thus, the possibility of $\mathrm{Au}$ atom to the crystal surface is strongly restricted and resulted in the formation of diffusioncontrolled morphologies [29]. Additionally, the addition of $\mathrm{AgNO}_{3}$ to the reaction solution provides an amount of $\mathrm{Ag}^{+}$ions, which is predicted to play an essential role in the growth mechanism of AuNSs. The explanation for the role of the $\mathrm{Ag}^{+}$ions was proposed based on the underpotential deposition of silver on the various facets of a gold crystal, further restricting the growth of initial particles and resulting in symmetry-breaking $[2,30]$. It was found that metallic silver strongly binds to the $\mathrm{Au}\{110\}$ surface, slowing down the growth rate of $\mathrm{Au}$ on these facets [2]. The other crystal facets could grow faster, leading to the formation of AuNSs. Additionally, the AuNSs synthesized with collagen are relatively small compared to previous studies with seed-mediated and one-step reduction methods (Table 3). 


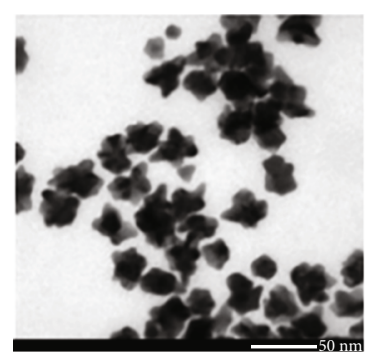

(a)

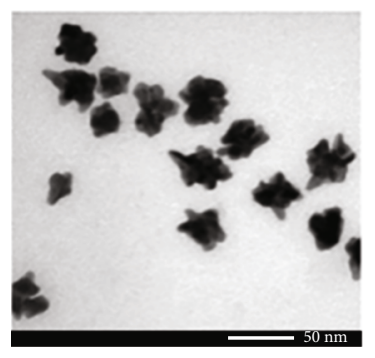

(c)

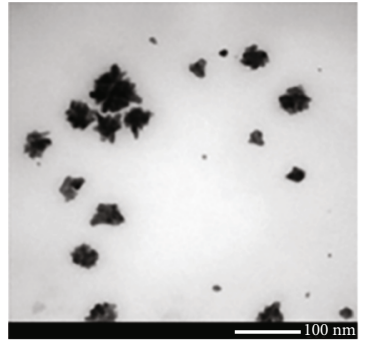

(e)

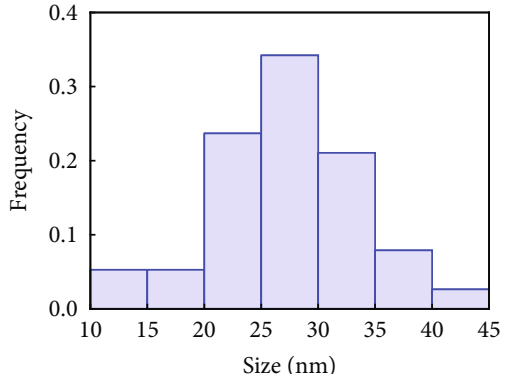

(b)

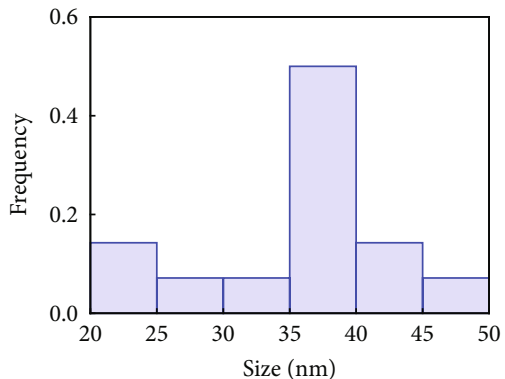

(d)

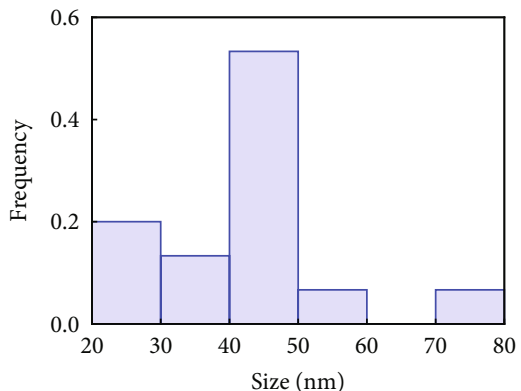

(f)

Figure 2: TEM images (a) scale bar $50 \mathrm{~nm}$, (c) scale bar $50 \mathrm{~nm}$, and (e) scale bar $100 \mathrm{~nm}$ and (b, d, f) corresponding histogram plot of the size distribution of gold nanostars synthesized at a different $\mathrm{pH}$ level of 3.0, 4.0, and 5.0, respectively.

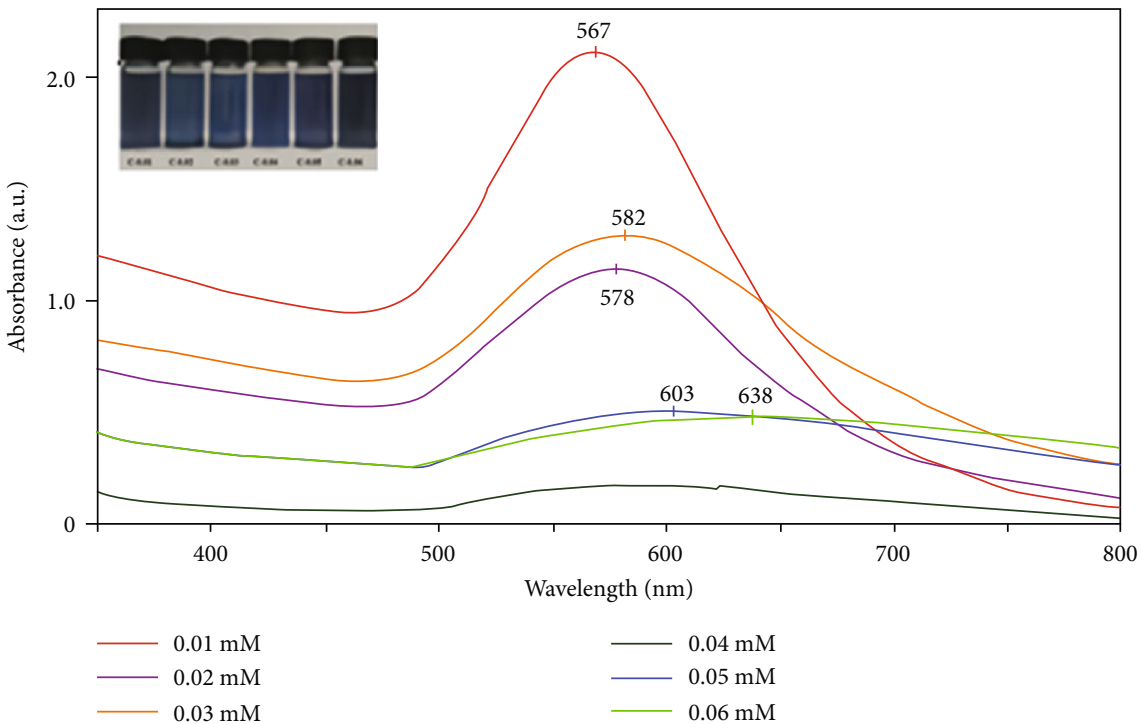

Figure 3: UV-Visible spectra of gold nanostructures were produced at various collagen concentrations of $0.01,0.02,0.03,0.04,0.05$, and $0.06 \mathrm{mM}$. Inserts display the color of Au colloids (left inset). 


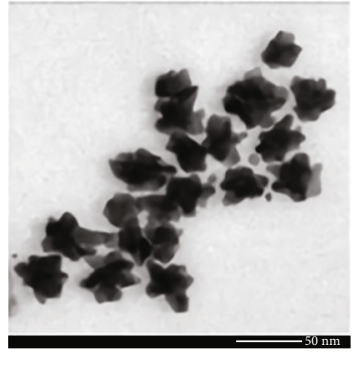

(a)

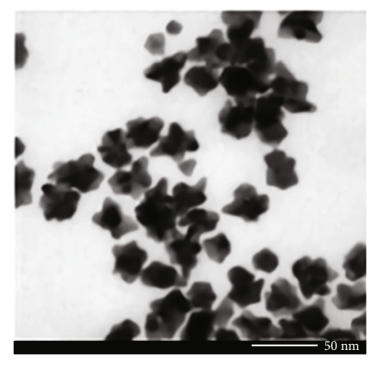

(c)

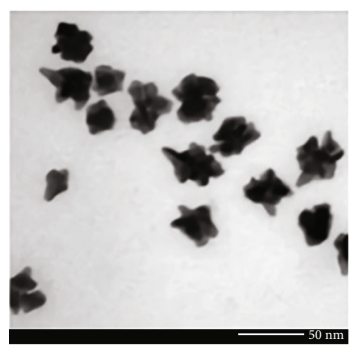

(e)

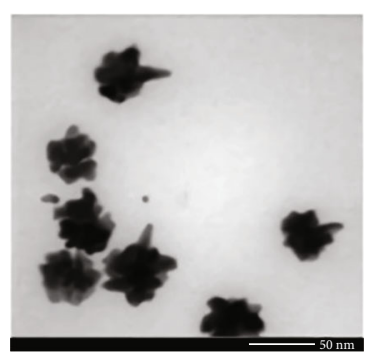

(g)

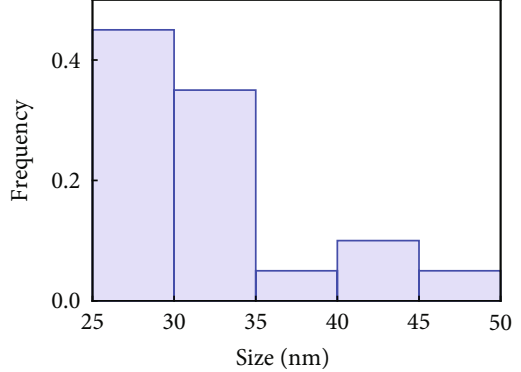

(b)

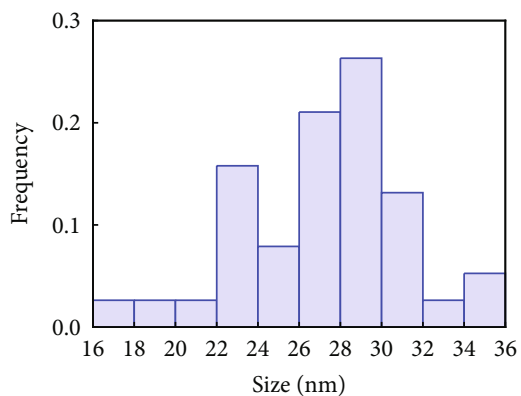

(d)

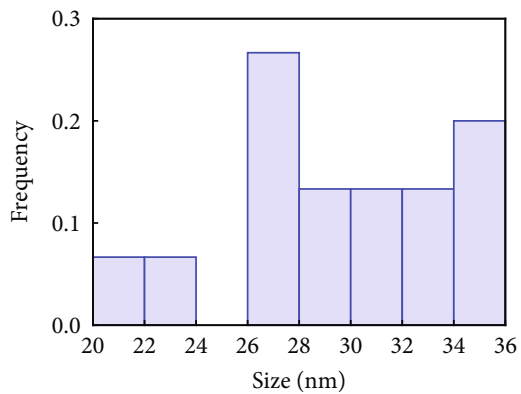

(f)

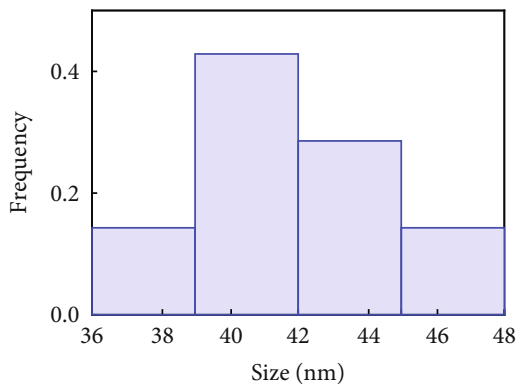

(h)

Figure 4: (a, c, e, g) TEM images (scale bars for all, 50nm) and (b, d, f, h) representative histogram of the size distribution of gold colloidal system synthesized with various collagen concentrations of $0.02,0.03,0.04$, and $0.05 \mathrm{mM}$, respectively.

To analyze the colloidal solution's purity, the sample of AuNS synthesized with the collagen concentration of $0.05 \mathrm{mM}$ was determined by energy-dispersive X-ray spectroscopy (EDS). The peak at $2.1 \mathrm{keV}$ was observed on the EDS elemental spectrum assigned to the Au signal. The EDS result presented in Figure 5 showed that AuNSs are composed of gold (95 atomic \%), and only a trace amount of chloride is observed ( 2 atomic \%), confirming the formation of the pure gold nanocrystal. The high-resolution transmission electron microscopy (HRTEM) study offers insight into the atomic structures of gold nanoparticles. Characteristic lattice fringes are observed in Figure 6 with a $d$ -spacing of $2.37 \AA$, which is assigned to $\{111\}$ lattice space of metallic gold [7], indicating the large exposed area of the corresponding facet.

3.3. X-Ray Diffraction and Selected Area Electron Diffraction of Gold Nanostars. Powder X-ray (XRD) was employed to determine the crystalline structure of the AuNSs. From XRD results of the gold nanostars synthesized with collagen, 
TABLe 3: Summary of the gold nanoparticles synthesized with different stabilizing agents.

\begin{tabular}{|c|c|c|c|c|c|c|}
\hline $\begin{array}{l}\text { Concentration of } \mathrm{HAuCl}_{4} / \\
\text { volume in water }\end{array}$ & Reaction condition & $\begin{array}{l}\text { Stabilizing } \\
\text { agent }\end{array}$ & Method & $\begin{array}{l}\text { AuNP size } \\
(\mathrm{nm})\end{array}$ & $\begin{array}{l}\text { AuNP } \\
\text { shape }\end{array}$ & Reference \\
\hline $\begin{array}{l}0.31 \mathrm{~g} \mathrm{HAuCl}_{4}, 0.39 \mathrm{~g} \mathrm{~N}^{-}(2- \\
\text { mercaptopropionyl)glycine }\end{array}$ & $\mathrm{NaBH}_{4}$ & Collagen & $\begin{array}{l}\text { Cross- } \\
\text { linking via } \\
\text { EDC }\end{array}$ & $2.4 \pm 0.7$ & Spherical & $\begin{array}{l}\text { Castaneda } \\
\text { et al. [37] }\end{array}$ \\
\hline $0.01 \mathrm{M} / 1.0 \mathrm{~mL}$ & Acid ascorbic & Chitosan & One-step & $111.3 \pm 56.2$ & Nanostar & $\begin{array}{c}\text { Phan et al. } \\
\text { [12] }\end{array}$ \\
\hline $0.04 \mathrm{mM} / 10 \mathrm{~mL}$ & CTAB $0.1 \mathrm{M}$, ascorbic acid $10 \mathrm{mM}$ & Chitosan & $\begin{array}{c}\text { Seed- } \\
\text { mediated }\end{array}$ & $70-100$ & Nanostars & $\begin{array}{l}\text { Baginskiy } \\
\text { et al. [11] }\end{array}$ \\
\hline $500 \mathrm{mM} / 5.0 \mu \mathrm{L}$ & $\begin{array}{c}10 \mu \mathrm{l} \text { of } \mathrm{NH}_{2} \mathrm{OH} \cdot \mathrm{HCl}, \mathrm{HAuCl}_{4}(1.0 \\
\mathrm{ml}, 2.5 \mathrm{mM})\end{array}$ & Lysin & $\begin{array}{c}\text { Seed } \\
\text { mediated }\end{array}$ & $97 \pm 22$ & Nanostars & $\begin{array}{l}\text { Avila-Alejo } \\
\text { et al. [38] }\end{array}$ \\
\hline $0.1 \mathrm{M} / 250 \mu \mathrm{L}$ & $\begin{array}{c}\text { CTAB }(10 \mathrm{~mL} / 0.1 \mathrm{M}) \mathrm{AgNO}_{3}(50 \mu \mathrm{l}, \\
0.1 \mathrm{M})\end{array}$ & & $\begin{array}{c}\text { Seed- } \\
\text { mediated }\end{array}$ & $55-105$ & Nanostars & $\begin{array}{c}\text { Khan et al. } \\
\text { [39] }\end{array}$ \\
\hline $25 \mathrm{mM}$ & $\begin{array}{c}\mathrm{AgNO}_{3} 10 \mathrm{mM}, \mathrm{pH} 4.0 \text {, and ascorbic } \\
\text { acid } 5.0 \mathrm{mM}\end{array}$ & $\begin{array}{l}\text { Collagen } \\
\text { type I }\end{array}$ & One-step & $27-41$ & Nanostars & This work \\
\hline $5 \mathrm{mM}$ & $\begin{array}{c}\text { Albumin solution (BSA, } 80 \mu \mathrm{L}, 10 \\
\mathrm{mg} / \mathrm{mL} \text { ), ascorbic acid } 100 \mathrm{mM}\end{array}$ & Albumin & One-step & 150 & Nanostars & $\begin{array}{l}\text { Sasidharan } \\
\text { et al. [40] }\end{array}$ \\
\hline $0.5 \mathrm{mM}$ & $\begin{array}{l}\text { PVP }\left(M_{w}=10,000 \text { g.mol }{ }^{-1} ; 10 \mathrm{mM}\right) \\
\text { in dimethyl formamide }(\mathrm{DMF})\end{array}$ & PVP & $\begin{array}{l}\text { Polymer } \\
\text { base }\end{array}$ & 40 & Nanostars & $\begin{array}{l}\text { Vanhecke } \\
\text { et al. [41] }\end{array}$ \\
\hline $0.25 \mathrm{mM}$ & Sodium citrate & $\begin{array}{l}\text { Gelatin type } \\
\text { A }\end{array}$ & One-step & $18 \pm 2$ & Spherical & $\begin{array}{l}\text { Suarasan } \\
\text { et al. [42] }\end{array}$ \\
\hline $0.254 \mathrm{mM}$ & Sodium citrate $25.4 \mathrm{mM}$ & $\begin{array}{l}\text { Collagen in } \\
\text { PBS }\end{array}$ & One-step & $10.2 \pm 2.7$ & Spherical & $\begin{array}{c}\text { Unser et al. } \\
{[43]}\end{array}$ \\
\hline $10 \mathrm{mM} / 0.1 \mathrm{~mL}$ & 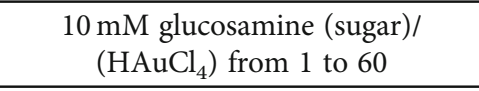 & Glucosamine & One-step & $55-72$ & Nanostars & $\begin{array}{l}\text { Moukarzel } \\
\text { et al. [44] }\end{array}$ \\
\hline $0.2 \%(\mathrm{w} / \mathrm{w})$ & Luminol in $0.1 \mathrm{~mol} / \mathrm{L} \mathrm{NaOH}$ & $\begin{array}{c}\text { Chitosan- } \\
\text { luminol }\end{array}$ & One-step & 90 & Nanoflower & $\begin{array}{c}\text { Wang et al. } \\
{[45]}\end{array}$ \\
\hline
\end{tabular}

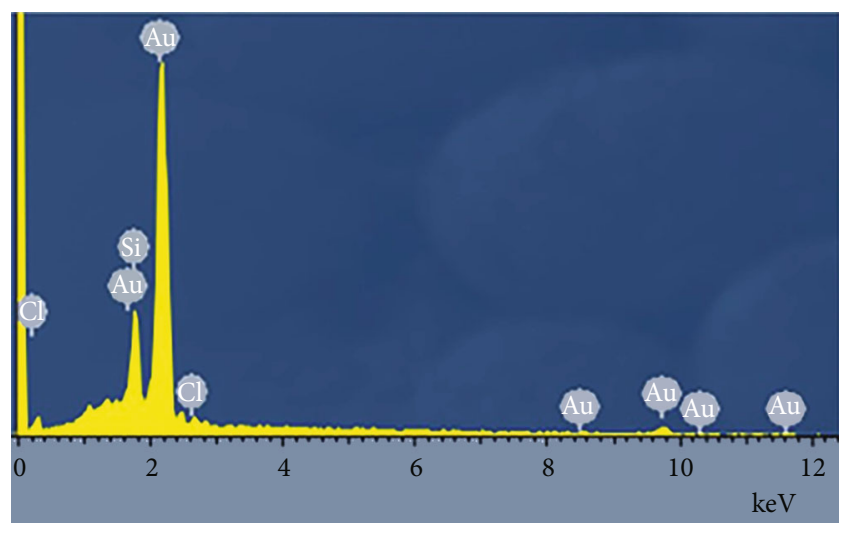

Figure 5: Energy-dispersive X-ray (EDS) elemental spectrum of gold nanostars synthesized with the collagen concentration of $0.05 \mathrm{mM}$.

there are diffraction peaks observed at $38.2^{\circ}, 44.4^{\circ}$, and $64.6^{\circ}$ in the $2 \Theta$ range of $25-70^{\circ}$ (Figure 7 ), indexed to $\{111\},\{200\}$, and $\{220\}$ lattice planes of the face-centered cubic (fcc) structure of gold with the Joint Committee on Powder Diffraction Standard (JCPDS) card number 00-004-084 [31, 32]. Among all, the highest diffraction peak is observed at $38.2^{\circ}$, corresponding to the $\{111\}$ lattice plane, attributed to the preferential growth of AuNSs along the $\{111\}$ plane. In

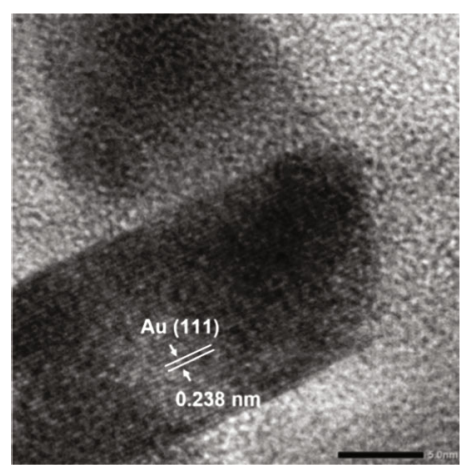

FIgURE 6: HRTEM image of AuNS-collagen obtained at $\mathrm{pH}$ of 4.0 with the collagen concentration of $0.05 \mathrm{mM}$ (scale bar $5 \mathrm{~nm}$ ).

particular, the $d$-spacing for multiple peaks can be calculated from the XRD data using Bragg's equation [33]

$$
n \lambda=2 d \sin \theta,
$$

where $\lambda=1.5406 \AA$ (wavelength of incident $\mathrm{X}$-ray), $\theta$ is the Bragg diffraction angle (in radian), $n=1$ (order of diffraction), and $d$ is interplanar spacing or $d$-spacing (in $\AA$ ). Furthermore, the experimental lattice constant value $a=$ $4.075 \AA$ is calculated for the cubic crystal system (Table 4) $[34,35]$. These results are in agreement with 


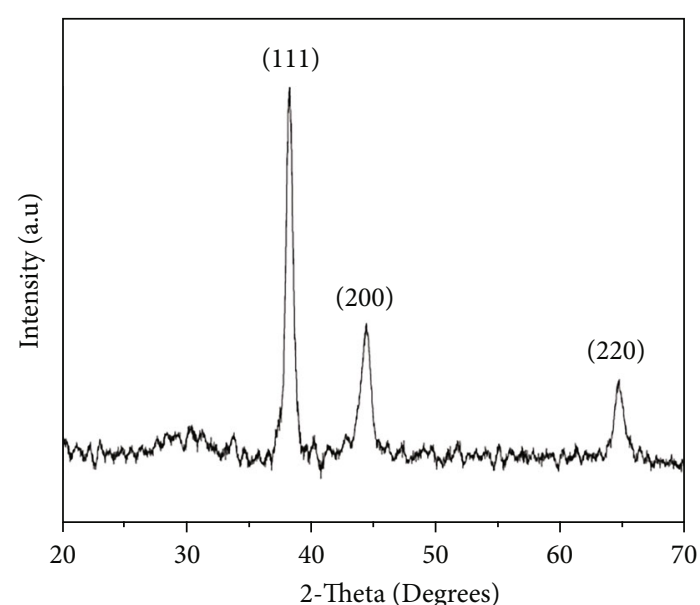

Figure 7: XRD pattern of AuNS controlled synthesis at collagen concentration of $0.05 \mathrm{mM}$.

TABLE 4: The calculation values of $d$-spacing and lattice constant from experimental XRD data.

\begin{tabular}{lccc}
\hline Lattice plane & 2-theta & Theta & $d$-spacing $(\AA)$ \\
\hline$(111)$ & 38.230 & 19.115 & 2.352 \\
$(200)$ & 44.358 & 22.179 & 2.040 \\
$(220)$ & 64.661 & 32.330 & 1.440 \\
\hline
\end{tabular}

HRTEM characterization that gold nanoparticles preferentially grow along $\{111\}$ direction.

The structure of the obtained nanoparticles was determined by the selected area electron diffraction (SAED) from the sample synthesized with a collagen concentration of $0.05 \mathrm{mM}$ at $\mathrm{pH} 4.0$. The pattern shown in Figure 8, composed of diffraction spots and blurred ring structure, revealed that the synthesized nanoparticles are crystalline structures. This blurred ring with diffraction spots in the SAED pattern could relate to the oriented crystallites [36] and be evident in the small size of nanoparticles. Furthermore, these diffraction spots can be indexed to the $\{111\}$ zone axis of cubic $\mathrm{Au}$, indicating that the $\{111\}$ plane is the top surface with the top normal to the electron beam.

3.4. Zeta Potential. Zeta potential is a crucial marker of the surface charge of the collagen-stabilized AuNS particles and the charged moieties of collagen molecules. As increased $\mathrm{pH}$ condition from 3.0 to 6.0 in the collagen solution, zeta potential progressively decreased from $+61.3 \mathrm{mV}$ at $\mathrm{pH} 3.0$ to $-5.2 \mathrm{mV}$ at $\mathrm{pH} 6.0$ (Figure 9 and Table 5). This result suggests that collagen isoelectric point (IEP) can be in the range of $\mathrm{pH}$ 5.5-6.0, in agreement with literature data for the IEP study of collagen derived from land animals by Park et al. [46] and pepsin-soluble collagen by Cruz-López et al. [47]. In addition, the IEP was also relevant to the charged composition and amino acid sequence on collagen [47, 48].

Zeta potential changes were observed when preparing AuNS with collagen. In the AuNS-collagen colloidal samples, the zeta potential value changed from 34.2 to $-2.7 \mathrm{mV}$

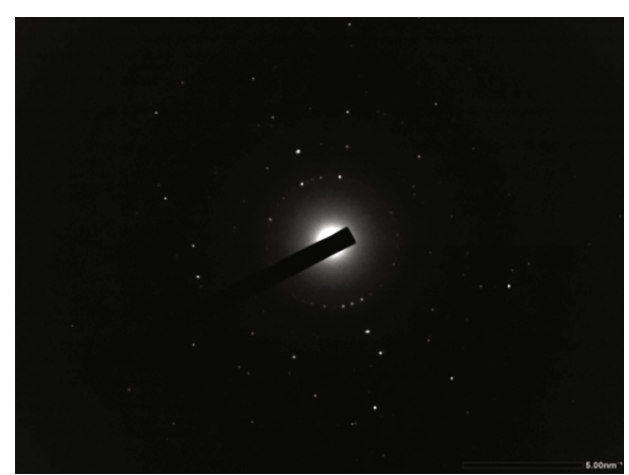

FIgURE 8: Selected area electron diffraction (SAED) pattern of gold nanostars obtained at $\mathrm{pH} 4.0$ and collagen concentration of $0.05 \mathrm{mM}$ (scale bar $5 \mathrm{~nm}$ ).

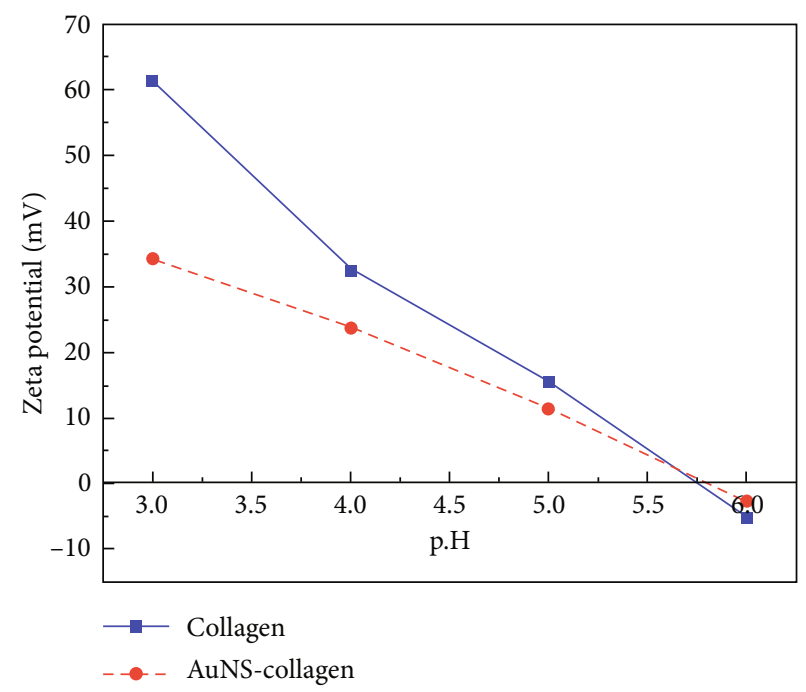

FIgURe 9: Zeta potential measurement of collagen and AuNScollagen prepared at different $\mathrm{pH}$ conditions from 3.0 to 6.0. The blue square represents collagen, and the red circle represents AuNS-collagen.

TABLE 5: The zeta potential value of collagen, AuNS-collagen, and AuNP synthesized without using collagen prepared at different $\mathrm{pH}$ conditions from 3.0 to 6.0 .

\begin{tabular}{lcc}
\hline & \multicolumn{2}{c}{ Zeta potential $(\mathrm{mV})$} \\
\hline $\mathrm{pH}$ condition & Collagen & AuNS-collagen \\
3 & +61.3 & +34.2 \\
4 & +32.4 & +23.7 \\
5 & +15.3 & +11.3 \\
6 & -5.2 & -2.7 \\
\hline
\end{tabular}

with increased $\mathrm{pH}$ from 3.0 to 6.0 (Table 5). The zeta potential values of AuNS-collagen colloidal samples are the high positive at $\mathrm{pH} 3.0-4.0(34.2-23.7 \mathrm{mV}$, respectively), reflecting the coverage and interaction of collagen molecules on nanoparticles surfaces $[49,50]$. Besides, the zeta potential value of AuNS-collagen at the $\mathrm{pH}$ of 6.0 was negative $(-2.7 \mathrm{mV})$ which might also be due to the influence of the negative 


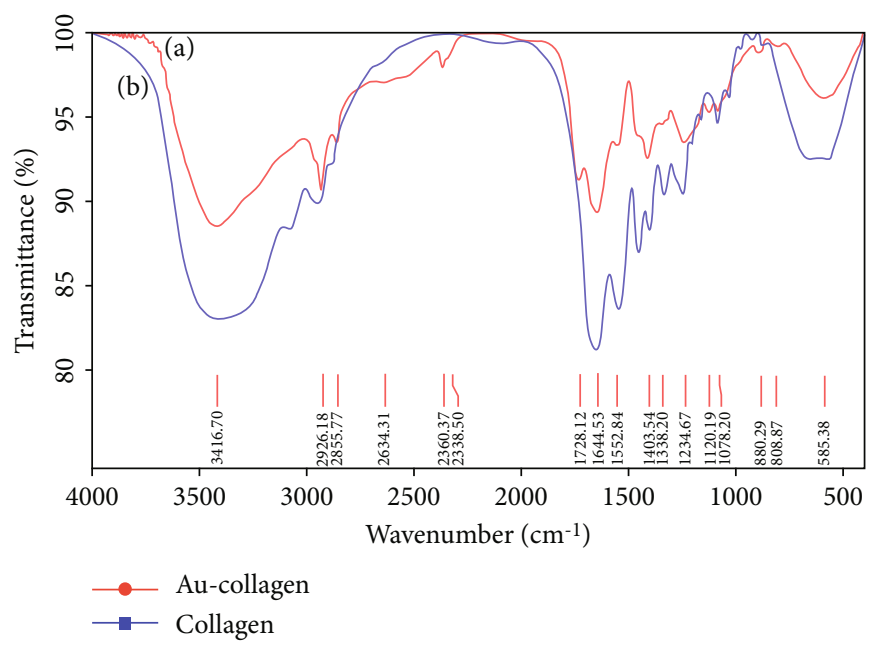

FIGURE 10: FT-IR spectra of collagen (curve b) and AuNS-collagen (curve a) (prepared at pH 4.0 and collagen concentration of $0.05 \mathrm{mM}$ ).

charge of collagen at this $\mathrm{pH}$ interval. These results suggested a close correlation between the charged compositions and the electrostatic interaction of collagen molecules with the gold nanoparticles.

3.5. FT-IR Spectroscopy. The interaction between various functional groups of collagen on nanoparticles surface was examined in the FT-IR spectrum of type I collagen (curve b) and the AuNS stabilized by collagen (curve a, Figure 10) (Table 6). The band around the region at $3200-3400 \mathrm{~cm}^{-1}$ observed in the collagen spectrum (curve b) assigned to the $\mathrm{N}-\mathrm{H}$ stretching vibration of the amide A group and could be overlapped on the hydroxyl group stretching band at $3406 \mathrm{~cm}^{-1}[51,52]$. In the AuNS-collagen spectrum (curve a), this band is shifted to $3416 \mathrm{~cm}^{-1}$ and decreased in intensity, indicating the interaction of Au nanoparticles with the collagen through the amine functional group. The band observed at $1650 \mathrm{~cm}^{-1}$ in the collagen spectrum (curve b) is attributed to the amide I band, mainly associated with the $\mathrm{C}=\mathrm{O}$ stretching, $\mathrm{C}-\mathrm{N}$ stretching, and $\mathrm{N}-\mathrm{H}$ bending vibration that corresponded to the secondary structure of collagen [52, 53]. This amide I band was also observed at $1644 \mathrm{~cm}^{-1}$ for AuNS-collagen with a significant change in intensity (curve a). The characteristic band of amide II groups appeared at $1544 \mathrm{~cm}^{-1}$ in the collagen spectrum (curve b), originating from the peptide C-N stretching and N-H bending vibrations [49], which slightly shifted to $1552 \mathrm{~cm}^{-1}$ for the AuNS-collagen sample (curve a). These changes could be relevant to the binding of acid amine on the collagen to the gold nanoparticles. Besides, the band observed at $1244 \mathrm{~cm}^{-1}$ in the collagen spectrum (curve b) was assigned for the amide III [49], which also shifted to $1234 \mathrm{~cm}^{-1}$ and decreased intensity in the AuNS-collagen spectrum. The appearance of bands at 1078 and $1120 \mathrm{~cm}^{-1}$ in AuNScollagen was related to the $\mathrm{C}-\mathrm{O}$ stretching vibration of $\mathrm{CH}$ $(\mathrm{OH})$ groups (Table 6) $[51,54,55]$. Only a small change compared with the 1081 and $1163 \mathrm{~cm}^{-1}$ bands on the collagen spectrum. These observation results indicate the possible interactions between the $\mathrm{Au}$ nanoparticles and collagen through either the free amine group or acid amine residues.
3.6. Separation and Quantification of AuNS-Collagen Colloidal Solution. For determining the appropriate centrifugation time to complete the separation of AuNS content in the colloidal sample, the UV-Vis spectra of each fraction were monitored through the change of the gold nanoparticle plasmonic peak in the range from 580 to $640 \mathrm{~nm}$. Figure 11 presents the UV-Vis spectra of three fractions of the colloidal sample after 80 minutes of centrifugation time included (a) AuNS total, (b) AuNS resuspended, and (c) AuNS supernatant. A slight change in the absorbance intensity was observed in the spectrum of AuNS total and AuNS resuspended fraction (curves a and b), indicating that most gold nanoparticles were deposited into the sediment fraction, and the AuNS formations were preserved after centrifugation. Moreover, none of the plasmonic peaks of AuNSs is detected in the spectrum of AuNS supernatant fraction (Figure 11, curve c), which can be reliably predicted for the absence of nanoparticles in this fraction. Thus, the separation of gold nanoparticles is complete, and the fractions could further be used for quantifying the Au content.

The obtained fractions were subsequently decomposed by the microwave-assisted digestion method before quantifying the gold content with the ICP-MS technique. Because the AuNSs were synthesized in collagen with complex matrices, the microwave-assisted acid decomposition procedure was suitable for digestion and accurate determination of Au contents $[19,60]$. Table 7 exhibits the gold quantification results of three fractions determined by ICP-MS. The gold concentration of AuNS total is $19.67 \mathrm{mg} \mathrm{L}^{-1}$, which could be involved nanoparticles or/and ionic forms of unreacted precursors. In the AuNS-resuspended fractions, the gold content measured by ICP-MS is approximately $17.46 \mathrm{mg} \mathrm{L}^{-}$ ${ }^{1}$, mainly attributed to the formation of AuNSs in the colloidal sample. Compared to the $\mathrm{Au}$ content determined in AuNS total, the obtained concentration of gold in the resuspended fraction shows the high yield and efficiency in the synthesis of AuNSs, presenting about $88.62 \%$ Au in colloidal solution. Additionally, the gold concentration of AuNSsupernatant fractions is determined as $2.13 \mathrm{mg} \mathrm{L}^{-1}$, the low concentration possibly due to the unreacted ions form 
TABLE 6: Fourier transform-infrared spectrum peak positions and assignment for collagen and AuNS-collagen.

\begin{tabular}{|c|c|c|c|}
\hline \multicolumn{2}{|c|}{ Wavenumber $\left(\mathrm{cm}^{-1}\right)$} & \multirow[b]{2}{*}{ Assignment } & \multirow[b]{2}{*}{ Reference } \\
\hline $\begin{array}{l}\text { AuNS-collagen } \\
\text { (curve a) }\end{array}$ & $\begin{array}{l}\text { Collagen solution } \\
\text { (curve b) }\end{array}$ & & \\
\hline 3416 & 3408 & $-\mathrm{OH}$ stretching & $\begin{array}{l}\text { Kumarie et al. } \\
{[51]}\end{array}$ \\
\hline- & $3200-3400$ & $\begin{array}{c}\text {-NH stretching } \\
\text { Amid A (amine group stretching vibrations overlapped on the side of } \\
\text { hydroxyl group) }\end{array}$ & $\begin{array}{l}\text { Kumarie et al. } \\
\quad[51] \\
\text { Sai et al. [56] }\end{array}$ \\
\hline 2926 & 2959 & Amide B (asymmetrical stretch of $\mathrm{CH}_{2}$ ) & $\begin{array}{l}\text { Li et al. [57] } \\
\text { Abe et al. [58] }\end{array}$ \\
\hline 1644 & 1650 & $\begin{array}{c}\text { Amide } \mathrm{I}(\mathrm{C}=\mathrm{O} \text { stretching, } \mathrm{C}-\mathrm{N} \text { stretching, and } \mathrm{N}-\mathrm{H} \text { bending } \\
\text { vibrations) }\end{array}$ & $\begin{array}{l}\text { Kadamchira et al. } \\
{[52]}\end{array}$ \\
\hline 1552 & 1544 & Amide II (C-N peptide stretching and $\mathrm{N}-\mathrm{H}$ bending vibrations & $\begin{array}{c}\text { Li et al. [57] } \\
\text { Rostek et al. [31] }\end{array}$ \\
\hline 1403 & 1402 & COO- symmetrical stretch & Jackson et al. [54] \\
\hline 1338 & 1334 & $\mathrm{CH}_{2}$ wagging vibration of proline & $\begin{array}{l}\text { Jackson et al. [54], } \\
\text { Li et al. [57] }\end{array}$ \\
\hline 1234 & 1244 & $\begin{array}{l}\text { Amide III ( } \mathrm{N}-\mathrm{H} \text { bending, } \mathrm{C}-\mathrm{N} \text { stretching vibrations) } \\
\text { Amide III }\left(\mathrm{CH}_{2} \text { wagging vibration of glycine }\right)\end{array}$ & $\begin{array}{l}\text { Payne et al. [59] } \\
\text { Rostek et al. [31] } \\
\text { Jackson et al. [54] }\end{array}$ \\
\hline 1120 & 1163 & $\mathrm{C}-\mathrm{O}$ stretching of $\mathrm{COH}$ & $\begin{array}{l}\text { Kumarie et al. } \\
{[51]}\end{array}$ \\
\hline 1078 & 1081 & C-O stretching vibration & Jackson et al. [54] \\
\hline 585 & $567-658$ & Skeletal stretch & Abe et al. [58] \\
\hline
\end{tabular}

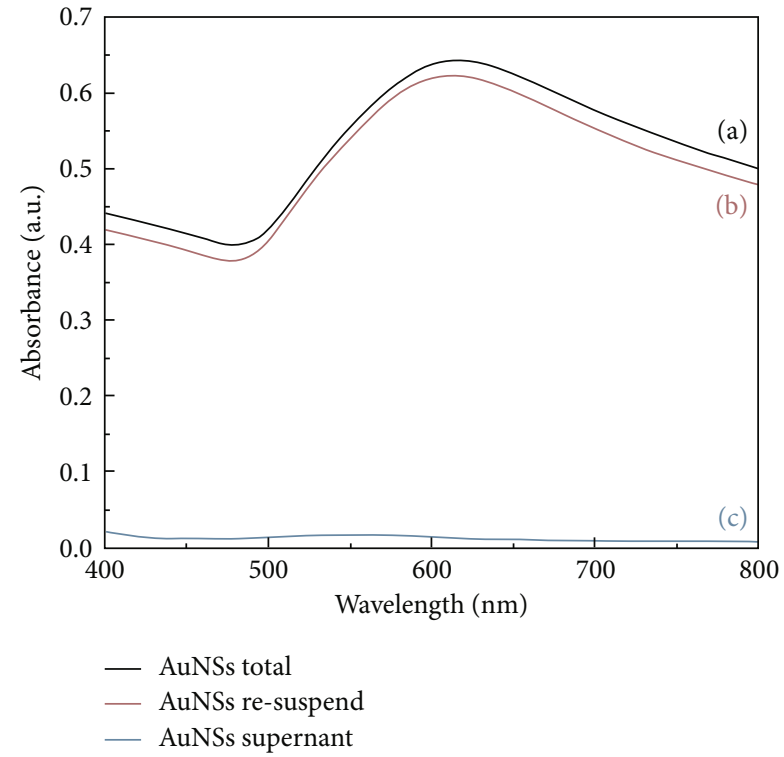

Figure 11: UV-Vis spectra of (a) AuNS total, (b) AuNS resuspended, and (c) AuNS supernatant fractions after the separation with the centrifugation time of 80 minutes at $9000 \mathrm{rpm}$.

$\left(\mathrm{Au}^{+}\right)$remaining in the liquid fractions. The quantification result of $\mathrm{Au}$ concentration determined by ICP-MS exhibits a high correlation with the UV-Vis characterization of the colloidal sample fractions, thus could prove that microwave-assisted acid digestion is suitable for evaluating the yield of synthesis AuNS-collagen.
TABle 7: Gold quantification in AuNS total, AuNS resuspended, and AuNS supernatant by ICP-MS.

\begin{tabular}{lcc}
\hline & $\begin{array}{c}\text { Au concentration } \\
\left(\mathrm{mg} \cdot \mathrm{L}^{-1}\right)\end{array}$ & $\begin{array}{c}\text { \% Au in colloidal } \\
\text { solution }\end{array}$ \\
\hline $\begin{array}{l}\text { AuNS total } \\
\text { AuNS } \\
\text { resuspended }\end{array}$ & 19.67 & 99.84 \\
$\begin{array}{l}\text { AuNS } \\
\text { supernatant }\end{array}$ & 17.46 & 88.62 \\
\hline
\end{tabular}

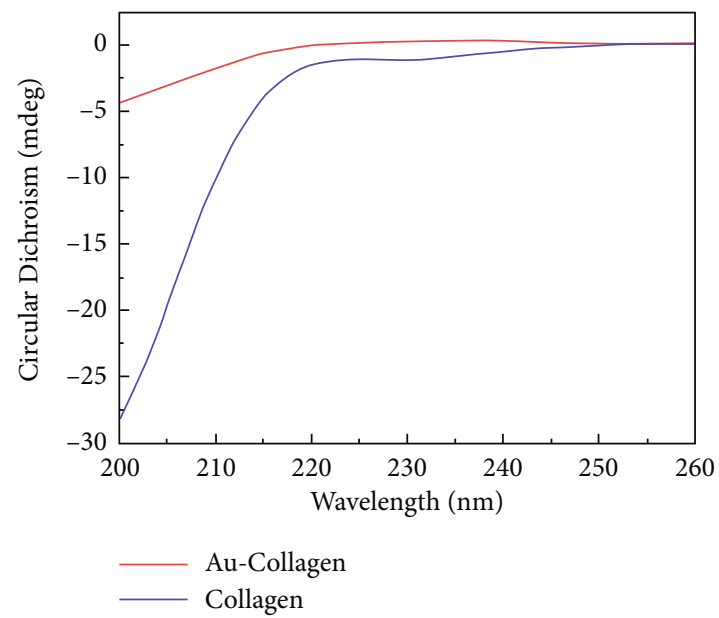

FIgURE 12: CD spectra of (a) Au-collagen and (b) collagen. 


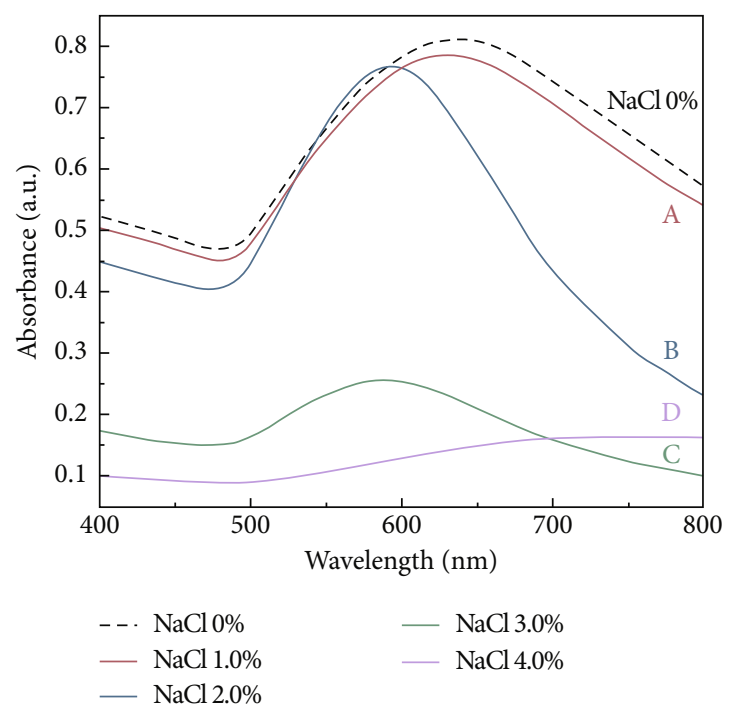

(a)

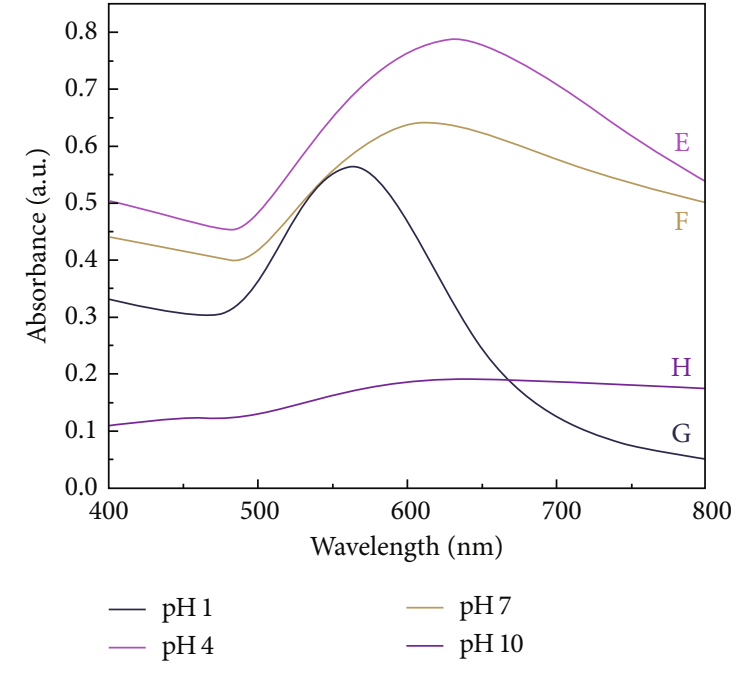

(b)

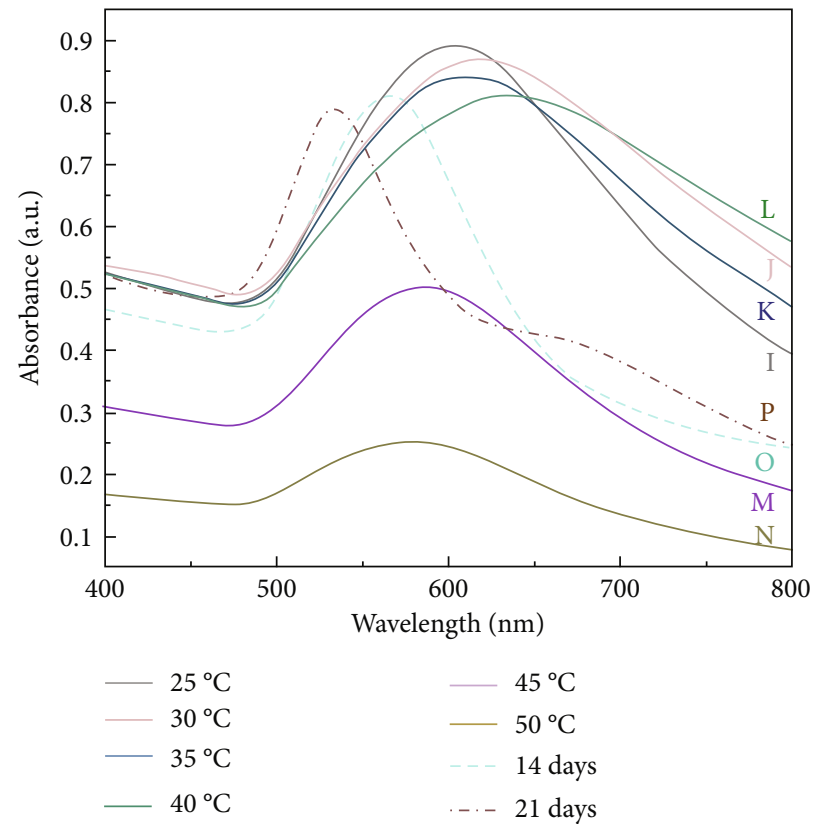

(c)

FIGURE 13: UV-Vis spectra of AuNS-collagen samples determined the stability (a) in different $\mathrm{NaCl}$ concentrations of $0,1.0,2.0,3.0$, and $4.0 \%(\mathrm{w} / \mathrm{v})$ (curves A-D); (b) under different $\mathrm{pH}$ conditions of $1,4,7$, and 10 (curves E-H) postsynthesis; and (c) at various temperatures from $25^{\circ} \mathrm{C}$ to $50^{\circ} \mathrm{C}$, storage 14 and 21 days postsynthesis (curves I to $\mathrm{P}$ ).

3.7. Circular Dichroism Analysis. The secondary structure contents, including $\alpha$-helix, $\beta$-sheet, and the random coil of protein, were determined through $\mathrm{CD}$ spectroscopy to understand the conformation of collagen molecules when interacting with the gold nanoparticles. The CD spectra of collagen and Au-collagen are presented in Figure 12. The absorption peak in the range from 200 to $250 \mathrm{~nm}$ was decreased in the spectra of Au-collagen samples. An increase in molar ellipticity at $220 \mathrm{~nm}$ is observed in the Au-collagen spectra. The calculation data based on adsorption peaks reveal the apparent changes in collagen secondary structure contents. Compared to the collagen, the secondary structure of the Au-collagen sample resulted in the decrease of $\alpha$-helix, $\beta$-turn, and random coil by $16.8 \%, 10.5 \%$, and $8.7 \%$, respectively. It could be inferred that the interaction with nanoparticles might reduce intramolecular hydrogen bonding and lead to hydrophobic group exposure, resulting in a decrease in $\alpha$-helix structure $[23,61]$. The random coil content of AuNS-collagen was slightly decreased, indicating that gold particles' binding might be attributed to the formation of a more compact secondary structure [62]. The CD data show that the deviations of collagen secondary structure conformation after interacting with gold nanoparticles are consistent with the FT-IR results. 
TABle 8: UV-Vis data of AuNS-collagen sample spectra for determining the colloidal stability at different $\mathrm{pH}, \mathrm{NaCl}$ concentrations, temperatures, and storage times.

\begin{tabular}{|c|c|c|c|}
\hline Sample condition & Curve & Wavelength of plasmon peak (nm) & Absorbance intensity (a.u.) \\
\hline $\mathrm{NaCl} 0 \%(\mathrm{w} / \mathrm{v})(0.05 \mathrm{mM}$ collagen $)$ & $\mathrm{NaCl} 0 \%$ & 634 & 0.809 \\
\hline $\mathrm{NaCl} 1.0 \%(\mathrm{w} / \mathrm{v})$ & A & 633 & 0.785 \\
\hline $\mathrm{NaCl} 2.0 \%(\mathrm{w} / \mathrm{v})$ & $\mathrm{B}$ & 592 & 0.767 \\
\hline $\mathrm{NaCl} 3.0 \%(\mathrm{w} / \mathrm{v})$ & $\mathrm{C}$ & 588 & 0.257 \\
\hline $\mathrm{NaCl} 4.0 \%(\mathrm{w} / \mathrm{v})$ & $\mathrm{D}$ & - & - \\
\hline pH 1 & G & 562 & 0.562 \\
\hline $\mathrm{pH} 4$ & $\mathrm{E}$ & 632 & 0.785 \\
\hline $\mathrm{pH} 7$ & $\mathrm{~F}$ & 617 & 0.642 \\
\hline $\mathrm{pH} 10$ & $\mathrm{H}$ & - & - \\
\hline $25^{\circ} \mathrm{C}$ & I & 602 & 0.893 \\
\hline $30^{\circ} \mathrm{C}$ & $\mathrm{J}$ & 618 & 0.867 \\
\hline $35^{\circ} \mathrm{C}$ & K & 610 & 0.841 \\
\hline $40^{\circ} \mathrm{C}$ & $\mathrm{L}$ & 633 & 0.809 \\
\hline $45^{\circ} \mathrm{C}$ & $\mathrm{M}$ & 588 & 0.501 \\
\hline $50^{\circ} \mathrm{C}$ & $\mathrm{N}$ & 576 & 0.251 \\
\hline 14 days postsynthesis & $\mathrm{O}$ & 564 & 0.811 \\
\hline 21 days postsynthesis & $\mathrm{P}$ & 534 & 0.788 \\
\hline
\end{tabular}

3.8. Stability of Collagen Stabilized Gold Nanoparticles. The colloidal stability of the AuNS-collagen samples against salt concentration was evaluated by UV-Vis spectroscopy for their further applications in the biomedical field. From the UV-Vis spectra presented in Figure 13(a), the AuNScollagen is stable in $\mathrm{NaCl}$ solutions up to the concentration of $2.0 \%(\mathrm{w} / \mathrm{v})$ (curves $\mathrm{A}$ and $\mathrm{B})$. A blue shift of plasmon bands and slightly reducing intensity (0.767) were observed at $592 \mathrm{~nm}$ for the AuNS-collagen after testing with 2.0\% (w/ v) $\mathrm{NaCl}$ solution (curve B). As increased in the $\mathrm{NaCl}$ concentration to $3.0 \%(\mathrm{w} / \mathrm{v})$, the plasmon peak for gold nanoparticles was unable to be detected (curve D). This change could be a sign of nanoparticle aggregation caused by the electrostatic repulsion force on the surface charge of nanoparticles in a high ion concentration environment. Furthermore, the solubility of collagen is strongly affected by the $\mathrm{NaCl}$ concentration, and it was reported that when in the high $\mathrm{NaCl}$ concentrations $(>3.0 \%(\mathrm{w} / \mathrm{v}))$, the collagen solubility decreased dramatically [49]. Increasing ionic salts could enhance the hydrophobic interaction of collagen chains, leading to protein precipitation $[57,63]$. The stabilizing ability of collagen on the gold nanoparticles was limited due to the low protein coverage, resulting in the self-aggregation of particles.

The AuNS-collagen colloidal solutions were also investigated for their stability under acidic and alkaline medium (1, 4,7 , and 10) in the aqueous solution by monitoring the changes in the surface resonance plasmon peaks of UV-Vis spectra exhibited in Figure 13(b). The plasmon peak with high intensity (0.785) was observed at $632 \mathrm{~nm}$ for AuNScollagen sample prepared at $\mathrm{pH}$ of 4 (curve E). The displacement of the plasmon peak at the shorter wavelength of $562 \mathrm{~nm}$ was obtained in the spectrum of $\mathrm{pH} 1$ sample with a slight reduction in intensity (0.562). It could be relevant to the change in size and morphology of gold nanoparticles, but the colloidal solution was considered stable in acidic conditions. After the increasing testing $\mathrm{pH}$ to 7 and 10 , only a plasmon peak with the intensity of 0.642 was observed at the wavelength of $617 \mathrm{~nm}$ for neutral condition (curve F), and almost no sign of plasmon peak for gold nanoparticles under alkaline condition (curve $\mathrm{H}$ ). The plasmon peak position and intensity changes are taken as proof that the colloidal solution remains stable under neutral $\mathrm{pH}$ and tends to aggregate in an alkaline medium. This colloidal instability could be explained based on the reduction of the collagen solubility in alkaline $\mathrm{pH}[47,64]$, directly resulting in a decrease in the protective ability of collagen on the gold nanoparticles.

The influence of the temperature and storage time was further analyzed to get more insight into the colloidal stability of AuNS-collagen. The colloidal samples were investigated with various temperatures $(25,30,35,40,45$, and $50^{\circ} \mathrm{C}$ ) and behaved differently regarding the change of plasmon peaks for gold nanoparticles (Figure 13(c)). In the $\mathrm{UV}$-Vis spectra of the AuNS-collagen sample heating at 25 and $30^{\circ} \mathrm{C}$, there is no significant change in the absorbance intensity of plasmon peak with the decrease from 0.893 to 0.867 (Table 8 , curves I and J), indicating that the formation of gold nanoparticles in the presence of collagen is relatively stable at these temperatures. As increasing to higher temperatures (from 35 to $50^{\circ} \mathrm{C}$ ), a significant drop in the intensity from 0.841 to 0.251 (Table 8 , curves $\mathrm{K}-\mathrm{N}$ ) was detected, suggesting the reduction of colloidal stability. It could be related to collagen denaturation at high temperatures mentioned in the Komsa-Penkova et al. work [65]. The effect of storage times on the AuNS-collagen colloidal stability was investigated at $25^{\circ} \mathrm{C}$ for over 21 days postsynthesis and further analyzed based on the UV-Vis spectrum. As observed in Figure 13(c), there is only a small change in peak intensity 
of 0.811 (curve O) and 0.788 (curve P) for 14 and 21 days of storage time. Additionally, blue shifts to the shorter wavelength were also detected in the spectrum of sample storage over 14 and 21 days, which could be due to the change in size and shape of nanoparticles $[1,66]$. These observation results showed that the AuNS-collagen colloidal solutions were stable over the storage time without occurring aggregation.

\section{Conclusion}

In summary, AuNSs have been successfully prepared with collagen through the new and direct one-pot reduction approach. Our study revealed that the AuNSs with controlled size and shape could be effectively obtained using appropriate collagen concentrations and acidic $\mathrm{pH}$ conditions. More importantly, the tips of star-liked crystal could be elongated with the increase of collagen concentration to $0.05 \mathrm{mM}$ at a $\mathrm{pH}$ condition of 4.0. The UV-Vis spectrum showed that the light absorbance depended on the morphology of gold nanoparticles and shifted to a longer wavelength with the increase of collagen concentration from $567 \mathrm{~nm}$ for $0.02 \mathrm{mM}$ to $603 \mathrm{~nm}$ for $0.05 \mathrm{mM}$. The EDS spectrum associated with HRTEM results confirms the formation of pure gold nanocrystals, and the SAED shows good agreement with the planes that appear in the XRD pattern. The FT-IR and CD analysis indicated the collagen interaction to gold nanoparticles mainly through the amine group and acid amine residues, followed by the collagen secondary structure change.

Furthermore, the use of collagen is vitally essential for the one-pot controlled synthesis AuNSs. The colloidal AuNS-collagen exhibited good stability in the low salt concentrations (below 2.0\%, w/v), mildly acidic, and neutral $\mathrm{pH}$ (from 4 to 7 ), but not qualified in the alkaline environment. Besides, the prepared AuNS-collagen was also stable in the low-temperature range from 25 to $40^{\circ} \mathrm{C}$. We found that collagen showed high feasibility in the preparation of AuNS, and this integrating nanomaterial could be favorable for application in the optical biosensor. Efforts in the biosensor application should be developed specifically for AuNScollagen material, mediated through the optical properties of gold nanostars, and various protocols for testing AuNScollagen in the biological environment need to be studied.

\section{Data Availability}

The data used to support the findings of this study are included within the article.

\section{Conflicts of Interest}

The authors declare no conflict of interest.

\section{Authors' Contributions}

Investigation was contributed by $\mathrm{H}$ T Ho, T P P Nguyen, Q $\mathrm{K}$ Vo, and A T Nguyen. Writing (original draft) was contributed by Q K Vo.

\section{Acknowledgments}

This research is funded by the University of Science VNUHCM under grant number HH 2021-02.

\section{References}

[1] K. L. Kelly, E. Coronado, L. L. Zhao, and G. C. Schatz, "The optical properties of metal nanoparticles: the influence of size, shape, and dielectric environment," The Journal of Physical Chemistry. B, vol. 107, no. 3, pp. 668-677, 2003.

[2] M. Grzelczak, J. Pérez-Juste, P. Mulvaney, and L. M. Liz-Marzán, "Shape control in gold nanoparticle synthesis," Chemical Society Reviews, vol. 37, no. 9, pp. 1783-1791, 2008.

[3] C. L. Nehl, H. Liao, and J. H. Hafner, "Optical properties of star-shaped gold nanoparticles," Nano Letters, vol. 6, no. 4, pp. 683-688, 2006.

[4] V. H. Segtnan and T. Isaksson, "Temperature, sample and time dependent structural characteristics of gelatine gels studied by near infrared spectroscopy," Food Hydrocolloids, vol. 18, no. 1, pp. 1-11, 2004.

[5] L. A. Dykman and N. G. Khlebtsov, "Multifunctional goldbased nanocomposites for theranostics," Biomaterials, vol. 108, pp. 13-34, 2016.

[6] J. Xiao and L. Qi, "Surfactant-assisted, shape-controlled synthesis of gold nanocrystals," Nanoscale, vol. 3, no. 4, pp. 1383-1396, 2011.

[7] L. Lu, K. Ai, and Y. Ozaki, "Environmentally friendly synthesis of highly monodisperse biocompatible gold nanoparticles with urchin-like shape," Langmuir, vol. 24, no. 3, pp. 1058-1063, 2008.

[8] Y. Xia and N. J. Halas, "Shape-controlled Synthesis and surface plasmonic Properties of Metallic nanostructures," MRS Bulletin, vol. 30, no. 5, pp. 338-348, 2005.

[9] P. Priecel, H. Adekunle Salami, R. H. Padilla, Z. Zhong, and J. A. Lopez-Sanchez, "Anisotropic gold nanoparticles: preparation and applications in catalysis," Chinese Journal of Catalysis, vol. 37, no. 10, pp. 1619-1650, 2016.

[10] P. Vijayaraghavan, C. H. Liu, and K. C. Hwang, "Synthesis of multibranched gold nanoechinus using a gemini cationic surfactant and its application for surface enhanced Raman scattering," ACS Applied Materials \& Interfaces, vol. 8, no. 36, pp. 23909-23919, 2016.

[11] I. Baginskiy, T. C. Lai, L. C. Cheng et al., "Chitosan-modified stable colloidal gold nanostars for the photothermolysis of cancer cells," Journal of Physical Chemistry C, vol. 117, no. 5, pp. 2396-2410, 2013.

[12] T. T. V. Phan, V. T. Nguyen, S. H. Ahn, and J. Oh, "Chitosanmediated facile green synthesis of size-controllable gold nanostars for effective photothermal therapy and photoacoustic imaging," European Polymer Journal, vol. 118, pp. 492-501, 2019.

[13] Y. Zhang, B. Wang, S. Yang, L. Li, and L. Guo, "Facile synthesis of spinous-like $\mathrm{Au}$ nanostructures for unique localized surface plasmon resonance and surface-enhanced Raman scattering," New Journal of Chemistry, vol. 39, no. 4, pp. 2551-2556, 2015.

[14] M. D. Shoulders and R. T. Raines, "Collagen structure and stability," Annual Review of Biochemistry, vol. 78, no. 1, pp. 929-958, 2009. 
[15] R. Parenteau-Bareil, R. Gauvin, and F. Berthod, "Collagenbased biomaterials for tissue engineering applications," Materials, vol. 3, no. 3, pp. 1863-1887, 2010.

[16] O. S. Rabotyagova, P. Cebe, and D. L. Kaplan, "Collagen structural hierarchy and susceptibility to degradation by ultraviolet radiation," Materials Science and Engineering: $C$, vol. 28, no. 8, pp. 1420-1429, 2008.

[17] P. Raveendran, J. Fu, and S. L. Wallen, "Completely 'green' synthesis and stabilization of metal nanoparticles," Journal of the American Chemical Society, vol. 125, no. 46, pp. 1394013941, 2003.

[18] R. M. Galazzi, E. D. B. Santos, T. Caurin, G. D. S. Pessôa, I. O. Mazali, and M. A. Z. Arruda, "The importance of evaluating the real metal concentration in nanoparticles post-synthesis for their applications: a case-study using silver nanoparticles," Talanta, vol. 146, pp. 795-800, 2016.

[19] N. V. Godoy, R. M. Galazzi, K. Chacón-Madrid, M. A. Arruda, and I. O. Mazali, "Evaluating the total gold concentration in metallic nanoparticles with a high content of organic matter through microwave-assisted decomposition platform and plasma-based spectrometric techniques (ICP-MS and ICP OES)," Talanta, vol. 224, article 121808, 2021.

[20] U. M. 3052, "Microwave assisted acid digestion of siliceous and organically based matrices," Tetrahedron, vol. 52, no. 44, pp. 13837-13866, 1996.

[21] B. L. Batista, D. Grotto, J. L. Rodrigues, V. C. de Oliveira Souza, and F. Barbosa, "Determination of trace elements in biological samples by inductively coupled plasma mass spectrometry with tetramethylammonium hydroxide solubilization at room temperature," Analytica Chimica Acta, vol. 646, no. 1-2, pp. 23-29, 2009.

[22] W. Wu, L. He, Y. Liang et al., "Preparation process optimization of pig bone collagen peptide-calcium chelate using response surface methodology and its structural characterization and stability analysis," Food Chemistry, vol. 284, pp. 8089, 2019.

[23] X. Yang, X. Yu, A. G. Yagoub et al., "Structure and stability of low molecular weight collagen peptide (prepared from white carp skin) -calcium complex," LWT, vol. 136, article 110335 , 2021.

[24] C. J. Murphy, T. K. Sau, A. M. Gole et al., "Anisotropic metal nanoparticles: synthesis, assembly, and optical applications," The Journal of Physical Chemistry B, vol. 109, no. 3-4, pp. 13857-13870, 2005.

[25] L. C. Cheng, J. H. Huang, H. M. Chen et al., "Seedless, silverinduced synthesis of star-shaped gold/silver bimetallic nanoparticles as high efficiency photothermal therapy reagent," Journal of Materials Chemistry, vol. 22, no. 5, pp. 2244-2253, 2012.

[26] F. Hao, C. L. Nehl, J. H. Hafner, and P. Nordlander, "Plasmon resonances of a gold nanostar," Nano Letters, vol. 7, no. 3, pp. 729-732, 2007.

[27] X. Mo, Y. An, C. S. Yun, and S. M. Yu, "Nanoparticle-assisted visualization of binding interactions between collagen mimetic peptide and collagen fibers," Angewandte Chemie, vol. 45, no. 14, pp. 2267-2270, 2006.

[28] D. Wang, J. Ye, S. D. Hudson, K. C. K. Scott, and S. Lin-Gibson, "Effects of nanoparticle size and charge on interactions with self-assembled collagen," Journal of Colloid and Interface Science, vol. 417, pp. 244-249, 2014.
[29] H. Imai, "Self-organized formation of hierarchical structures," Topics in Current Chemistry, vol. 270, pp. 43-72, 2006.

[30] M. Liu and P. Guyot-Sionnest, "Mechanism of silver(I)assisted growth of gold nanorods and bipyramids," The Journal of Physical Chemistry. B, vol. 109, no. 47, pp. 22192-22200, 2005.

[31] A. Rostek, K. Loza, M. Heggen, and M. Epple, "X-ray powder diffraction to analyse bimetallic core-shell nanoparticles (gold and palladium; 7-8 nm)," RSC Advances, vol. 9, no. 46, pp. 26628-26636, 2019.

[32] K. Xin Lee, K. Shameli, M. Miyake et al., "Green synthesis of gold nanoparticles using aqueous extract of Garcinia mangostana fruit peels," Journal of Nanomaterials, vol. 2016, 7 pages, 2016.

[33] W. H. Bragg and W. L. Bragg, "The reflection of X-rays by crystals," Proceedings of the Royal Society of London, Series A, vol. 88, no. 605, pp. 146-152, 1913.

[34] E. R. Jette and F. Foote, "Precision determination of lattice constants," The Journal of Chemical Physics, vol. 3, no. 10, pp. 605-616, 1935.

[35] C. Wang, H. Wang, T. Huang, X. Xue, F. Qiu, and Q. Jiang, "Generalized-stacking-fault energy and twin-boundary energy of hexagonal close-packed Au: a first-principles calculation," Scientific Reports, vol. 5, no. 5988, pp. 1-11, 2015.

[36] S. Pedireddy, H. K. Lee, W. W. Tjiu et al., "One-step synthesis of zero-dimensional hollow nanoporous gold nanoparticles with enhanced methanol electrooxidation performance," Nature Communications, vol. 5, no. 1, pp. 1-9, 2014.

[37] L. Castaneda, J. Valle, N. Yang, S. Pluskat, and K. Slowinska, "Collagen cross-linking with Au nanoparticles," Biomacromolecules, vol. 9, no. 12, pp. 3383-3388, 2008.

[38] J. O. Avila-Alejo, A. K. González-Palomo, G. PlascenciaVilla, M. José-Yacamán, H. R. Navarro-Contreras, and I. N. Pérez-Maldonado, "Low cytotoxicity of anisotropic gold nanoparticles coated with lysine on peripheral blood mononuclear cells "in vitro", Environmental Toxicology and Pharmacology, vol. 56, no. 550, pp. 210-218, 2017.

[39] H. I. Khan, M. U. Khalid, A. Abdullah et al., "Facile synthesis of gold nanostars over a wide size range and their excellent surface enhanced Raman scattering and fluorescence quenching properties," Journal of Vacuum Science \& Technology B, Nanotechnology and Microelectronics, vol. 36, no. 3, article 03E101, 2018.

[40] S. Sasidharan, D. Bahadur, and R. Srivastava, "Rapid, one-pot, protein-mediated green synthesis of gold nanostars for computed tomographic imaging and photothermal therapy of cancer," ACS Sustainable Chemistry \& Engineering, vol. 5, no. 11, pp. 10163-10175, 2017.

[41] D. Vanhecke, L. Rodríguez-Lorenzo, C. Kinnear, E. Durantie, B. Rothen-Rutishauser, and A. Petri-Fink, "Assumption-free morphological quantification of single anisotropic nanoparticles and aggregates," Nanoscale, vol. 9, no. 15, pp. 49184927, 2017.

[42] S. Suarasan, M. Focsan, D. Maniu, and S. Astilean, "Gelatinnanogold bioconjugates as effective plasmonic platforms for SERS detection and tagging," Colloids and Surfaces B: Biointerfaces, vol. 103, pp. 475-481, 2013.

[43] S. Unser, S. Holcomb, R. Cary, and L. Sagle, "Collagen-gold nanoparticle conjugates for versatile biosensing," Sensors, vol. 17, no. 2, p. 378, 2017. 
[44] W. Moukarzel, J. Fitremann, and J. D. Marty, "Seed-less amino-sugar mediated synthesis of gold nanostars," Nanoscale, vol. 3, no. 8, pp. 3285-3290, 2011.

[45] W. Wang and H. Cui, "Chitosan-luminol reduced gold nanoflowers: from one-pot synthesis to morphologydependent SPR and chemiluminescence sensing," Journal of Physical Chemistry C, vol. 112, no. 29, pp. 1075910766, 2008.

[46] S.-H. Park, T. Song, T. S. Bae et al., "Comparative analysis of collagens extracted from different animal sources for application of cartilage tissue engineering," International Journal of Precision Engineering and Manufacturing, vol. 13, no. 11, pp. 2059-2066, 2012.

[47] H. Cruz-López, S. Rodríguez-Morales, L. M. Enríquez-Paredes et al., "Comparison of collagen characteristic from the skin and swim bladder of Gulf corvina (Cynoscion othonopterus)," Tissue \& Cell, vol. 72, p. 101593, 2021.

[48] S. Morozova and M. Muthukumar, "Electrostatic effects in collagen fibril formation," The Journal of Chemical Physics, vol. 149, no. 16, article 163333, 2018.

[49] W. H. Zhao, C. F. Chi, Y. Q. Zhao, and B. Wang, "Preparation, physicochemical and antioxidant properties of acid- and pepsin-soluble collagens from the swim bladders of miiuy croaker (miichthys miiuy)," Marine Drugs, vol. 16, no. 5, p. 161, 2018.

[50] W. Wang, X. Ding, Q. Xu, J. Wang, L. Wang, and X. Lou, "Zeta-potential data reliability of gold nanoparticle biomolecular conjugates and its application in sensitive quantification of surface absorbed protein," Colloids and Surfaces. B, Biointerfaces, vol. 148, pp. 541-548, 2016.

[51] K. Kumari, P. Singh, and G. K. Mehrotra, "A facile one pot synthesis of collagen protected gold nanoparticles using Namalanodialdehyde," Materials Letters, vol. 79, pp. 199-201, 2012.

[52] A. Kandamchira, S. Selvam, N. Marimuthu, S. Kalarical Janardhanan, and N. N. Fathima, "Influence of functionalized nanoparticles on conformational stability of type I collagen for possible biomedical applications," Materials Science and Engineering: C, vol. 33, no. 8, pp. 4985-4988, 2013.

[53] C. Stani, L. Vaccari, E. Mitri, and G. Birarda, "FTIR investigation of the secondary structure of type I collagen: new insight into the amide III band," Spectrochimica Acta Part A: Molecular and Biomolecular Spectroscopy, vol. 229, article 118006, 2020.

[54] M. Jackson, L. P.'. Choo, P. H. Watson, W. C. Halliday, and H. H. Mantsch, "Beware of connective tissue proteins: assignment and implications of collagen absorptions in infrared spectra of human tissues," Biochimica et Biophysica ActaMolecular Basis of Disease, vol. 1270, no. 1, pp. 1-6, 1995.

[55] D. V. Svintradze, G. M. Mrevlishvili, N. Metreveli et al., "Collagen-DNA complex," Biomacromolecules, vol. 9, no. 1, pp. 21-28, 2008.

[56] K. Purna Sai and M. Babu, "Studies on Rana tigerina skin collagen," Comparative Biochemistry and Physiology Part B: Biochemistry and Molecular Biology, vol. 128, no. 1, pp. 81-90, 2001.

[57] Z.-R. Li, B. Wang, C.-f. Chi et al., "Isolation and characterization of acid soluble collagens and pepsin soluble collagens from the skin and bone of Spanish mackerel (Scomberomorous niphonius)," Food Hydrocolloids, vol. 31, no. 1, pp. 103113, 2013.
[58] Y. Abe and S. Krimm, "Normal vibrations of crystalline polyglycine I," Biopolymers, vol. 11, no. 9, pp. 1817-1839, 1972.

[59] K. J. Payne and A. Veis, "Fourier transform ir spectroscopy of collagen and gelatin solutions: deconvolution of the amide I band for conformational studies," Biopolymers, vol. 27, no. 11, pp. 1749-1760, 1988 .

[60] A. L. Fabricius, L. Duester, B. Meermann, and T. A. Ternes, "ICP-MS-based characterization of inorganic nanoparticlessample preparation and off-line fractionation strategies," Analytical and Bioanalytical Chemistry, vol. 406, no. 2, pp. 467-479, 2014.

[61] C. Wen, J. Zhang, J. Zhou, Y. Duan, H. Zhang, and H. Ma, "Effects of slit divergent ultrasound and enzymatic treatment on the structure and antioxidant activity of arrowhead protein," Ultrasonics Sonochemistry, vol. 49, pp. 294-302, 2018.

[62] K. Zhang, J. Li, H. Hou, H. Zhang, and B. Li, "Purification and characterization of a novel calcium-biding decapeptide from Pacific cod (Gadus Macrocephalus) bone: Molecular properties and calcium chelating modes," Journal of Functional Foods, vol. 52, pp. 670-679, 2019.

[63] Y. Tan and S. K. C. Chang, "Isolation and characterization of collagen extracted from channel catfish (Ictalurus punctatus) skin," Food Chemistry, vol. 242, pp. 147-155, 2018.

[64] T. M. T. Truong, V. M. Nguyen, T. T. Tran, and T. M. T. Le, "Characterization of acid-soluble collagen from food processing by-products of snakehead fish (Channa striata)," Processes, vol. 9, no. 7, p. 1188, 2021.

[65] R. Komsa-penkova, R. Koynova, G. Kostov, and B. G. Tenchov, "Thermal stability of calf skin collagen type I in salt solutions," vol. 1297, no. 2, pp. 171-181, 1996.

[66] P. N. Njoki, S. I-Im, D. M. Lim et al., "Size correlation of optical and spectroscopic properties for gold nanoparticles," Journal of Physical Chemistry C, vol. 111, no. 40, pp. 14664-14669, 2007. 